\title{
LA REDEFINICIÓN DE LOS ACTORES Y DE LA GEOGRAFÍA POLÍTICA EN EL PERÚ A FINALES DEL SIGLO XIX
}

\begin{abstract}
RESUMEN
El artículo analiza las razones que en el Perú de finales del siglo XIX motivaron la decisión de otorgar el derecho de voto solo a los alfabetizados y de introducir el sufragio directo, así como las consecuencias de tales medidas, que llevaron a la restricción del cuerpo electoral y a la introducción de novedades decisivas en el perfil del ciudadano, en la geografía política del país y en los criterios de selección del personal parlamentario. Detrás de estas medidas se encontraba la voluntad de la élite de gobierno de proponer y construir un proyecto político modernizador y una nueva idea del Estado y de la nación, para la cual, en el clima cultural de la época, la población indígena se consideraba inútil e inapropiada. Para desarrollar este tema se utilizan fuentes de distinta naturaleza: textos legislativos y constitucionales, debates parlamentarios, registros y actas electorales.
\end{abstract}

Palabras clave: Perú, siglo XIX, normas electorales, sufragio, indígenas, élites políticas, geografía política, cultura política.

\begin{abstract}
The article analyzes the reasons that motivated the decision to guarantee voting rights to literate people only in Peru and the change towards a direct suffrage. This brought consequences such as the restriction of the electoral body, the introduction of changes in the citizen profile, the political geography of the country and the selection criteria for members of the parliament. Behind these measures taken by government elites was the attempt to propose the construction of a modernizing political project and the idea of a new kind of State and Nation. Indigenous people were considered useless and inappropriate for these projects. Different primary sources were used to explore these topics, including legislative and constitutional documents, parliamentary debates as well as electoral registers and minutes.
\end{abstract}

Key words: Peru, Nineteenth century, Electoral regulations, Suffrage, Indians, Political elites, Political geography, Political culture.

Fecha de recepción: febrero de 2009

Fecha de aceptación: agosto de 2009

* Profesora asociada, docente de Historia de América Latina en la Facultad de Letras y Filosofía, Universidad de Padua (Italia).Correo electrónico: gabriella.chiaramonti@unipd.it 
Dos consideraciones, que me arriesgaría a definir como prejuicios, han desanimado hasta hace poco a los estudiosos peruanistas y latinoamericanistas en general, a analizar de manera exhaustiva las normas y las prácticas que en el siglo XIX caracterizaron la ciudadanía política y, en particular, el ejercicio del sufragio. Por un lado, ha sido extensa y duradera la convicción de que las leyes y constituciones eran ineficaces o fácil y constantemente inobservadas, debido a acciones ilegales o corruptas. Por otro lado, tanto en el Perú como en el resto de América Latina, ha sido muy tenaz la idea de que las elecciones eran poco más que una farsa, cuya reiteración se tenía que considerar absurda, inexplicable y sin interés para los historiadores, por la falta de significativas consecuencias, en un contexto político dominado por la acción de caudillos o de oligarcas todopoderosos.

Por supuesto, no se puede negar que tales convicciones tienen su propio fundamento, pero es verdad también que violencias, fraudes, corrupción e incumplimiento de las leyes no son un rasgo específico ni del Perú ni de América Latina y que es necesario, antes que nada, definir con precisión lo que se entiende por prácticas ilegales en relación con los diferentes contextos históricos y sociales, nacionales y locales, y las normativas vigentes; qué es lo que pertenece al ámbito de la corrupción y qué es lo que hay que incluir en la categoría genérica de las presiones ejercidas sobre el electorado ${ }^{1}$. Limitarse a la denuncia y reprobación de violencias e ilegalidades no llevaría sino a la elaboración de un enésimo capítulo de la plurisecular 'disputa' sobre la 'inmadurez' americana y su incapacidad para comprender y utilizar correctamente los mecanismos y las lógicas de la representación moderna ${ }^{2}$.

Como es bien notorio, sobre todo a partir de la mitad de los años 80 del siglo pasado, una producción historiográfica cada vez más abundante refutó estas convicciones, poniendo en evidencia la potencialidad heurística de un campo de estudio que se revela particularmente rico y de muchos matices, sobre todo si, en vez de considerar al sufragio en sí y sus resultados, nos ponemos ante una perspectiva diferente, que tenga en consideración las normas que definen la ciudadanía en un contexto particular y que por ello analice la relación entre titulares del derecho de voto y la sociedad en su conjunto y las prácticas a las que esto da lugar ${ }^{3}$. Por otro

Véanse las consideraciones contenidas en Eduardo Posada-Carbó, "Electoral Jugglig. A Comparative History of the Corruption of Suffrage in Latin America, 1830-1930", en Journal of Latin American Studies 32, Cambridge, 2000, 611-644; y en Walter Little y Eduardo Posada-Carbó (eds.), Political Corruption in Europe and Latin America, London-New York, MacMillan Press and St. Martin Press, 1996.

2 Tomo el término 'disputa' del ya clásico estudio de Antonello Gerbi, La disputa del Nuovo Mondo. Storia di una polemica: 1750-1900, Milano-Napoli, Riccardo Ricciardi Editore, 1983.

3 Para indicaciones sobre la bibliografía reciente acerca de la cuestión de la ciudadanía política en todos sus aspectos, véase Hilda Sábato, "La ciudadanía en el siglo XIX: nuevas perspectivas para el estudio del poder político en América Latina”, en Hans Joachim König, Tristan Platt y Colin Lewis (coords.), Cuadernos de Historia Latinoamericana 8: Estado-nación, Comunidad Indígena, Industria. Tres debates al final del Milenio, Ridderker, 2000, 49-70. Consultar, además, Marta Irurozqui, La ciudadanía en debate en América Latina. Discusiones historiográficas y una propuesta teórica sobre el valor público de la infracción electoral, Lima, Instituto de Estudios Peruanos, Documento de trabajo $\mathrm{N}^{\circ} 139$, 2004. Con respecto al caso peruano, ver Valentín Paniagua Corazao, Los orígenes del gobierno representativo en el Perú: las elecciones (1809-1826), Lima, Pontificia Universidad Católica 
lado, es verdad que constituciones y leyes -las electorales en particular, que a menudo son precedidas por largos e intensos debates- pueden proporcionar elementos útiles para indagar, primero, la visión que en un momento dado las élites políticas y de gobierno elaboraron sobre la situación de su propio país y, segundo, los proyectos que esas mismas élites pensaron llevar a cabo, cambiando las reglas preexistentes.

En las siguientes páginas, me propongo analizar las razones y los objetivos de la reforma aprobada en el Perú en $1895^{4}$, la cual eliminó los requisitos de tipo censitario y/o capacitario previstos por la Constitución vigente, limitando el derecho de sufragio solo a los alfabetizados mayores de 21 años o casados, y que constituyó la premisa para el definitivo paso al sufragio directo, sancionado por la nueva ley electoral de $1896^{5}$.

Se trata de una reforma a primera vista sorprendente, que contradice, tanto la idea difundida de un panorama electoral que en el país andino se mantendría sustancialmente uniforme a lo largo del siglo XIX, como todo modelo de tipo evolucionista, según el cual la historia del sufragio habría estado caracterizada por

del Perú-Fondo de Cultura Económica, 2003; Cristóbal Aljovín de Losada y Sinesio López (ed.), Historia de las elecciones en el Perú. Estudios sobre el gobierno representativo, Lima, Instituto de Estudios Peruanos, 2005; Gabriella Chiaramonti, Ciudadanía y representación en el Perú (18081861). Los itinerarios de la soberanía, Lima, Universidad Nacional Mayor de San Marcos-ONPE, 2005. Por otra parte, información sobre la historiografía electoral reciente para el caso peruano se encuentra en la sección dedicada al capítulo sobre "Los trabajos eleccionarios" en la "Bibliografía anotada" del libro de Carmen McEvoy, Homo políticus. Manuel Pardo, la política peruana y sus dilemas, 1871-1878, Lima, PUCP-Instituto Riva-Agüero-IEP-ONPE, 2007, 367-371, y de manera muy detallada en los artículos de Cristobal Aljovín de Losada y Francisco Núñez Díaz, "Ensayo bibliográfico: las elecciones peruanas decimonónicas", y de José Ragas Rojas, "Clío en las urnas. La historiografía electoral sobre el Perú. Estado de la cuestión y guía bibliográfica (1810-1930)”, en Elecciones 6, Lima, 2006, 219-242 y 243-272. El N 7 de la misma revista, de 2007, también posee artículos sobre asuntos electorales del siglo XIX.

4 "Ley reformando el artículo 38 de la Constitución", en República del Perú. Ministerio de Gobierno y Policía, Leyes, decretos y resoluciones expedidas por el Ministerio de Gobierno y Policía, arregladas por el Sr. Director de Gobierno D. D. Juan José Calle, tomo II, Lima, Imprenta La Industria, 1899, 154.

5 Ver Mariano Lino Cornejo, Ley electoral dada por la legislatura Extraordinaria de 1896. Con citas, notas, concordancias y un Apéndice, Lima, Imprenta del Estado, 1901, 3-41. En Brasil, en 1881, se había aprobado una norma parecida, la "Lei Saraiva", por la cual, desde aquel año, no podían inscribirse en los registros electorales nuevos votantes analfabetos. Se mantuvo esta ley, aun cuando, en 1891, fue aprobada la nueva Constitución republicana federal. La Constitución de 1824 (cuyas indicaciones en materia de sufragio fueron sustancialmente confirmadas por la ley electoral de 1846 , en vigencia hasta 1881) no establecía requisitos de raza o grado de alfabetización, y el requisito de propiedad era bajo (100 mil reis de ingreso neto anual, cifra que fue elevada a 200 mil en 1846 , equivalentes a aproximadamente 100 dólares). Para dar un ejemplo, en las elecciones primarias de 1872 sufragaron alrededor de un millón de votantes (el $53 \%$ de los hombres con más de 25 años y el $43 \%$ de la población de edad superior a los 21), mientras que después de la reforma, los que tenían derecho a sufragio se redujeron a algo más de 100.000. Véase Richard Graham, "Formando un gobierno central: las elecciones y el orden monárquico en el Brasil del siglo XIX”, en Antonio Annino (coord.), Historia de las elecciones en Iberoamérica, siglo XIX. De la formación del espacio político nacional, Buenos Aires, Fondo de Cultura Económica, 1995, 347-379: 357-359; y José Murilo de Carvalho, "Dimensiones de la ciudadanía en el Brasil del siglo XIX", en Hilda Sábato (coord.), Ciudadanía política y formación de las naciones. Perspectivas históricas de América Latina, México D.F., Colegio de México, Fideicomiso Historia de las Américas, 1999, 321-344: 327-328. En Brasil, los analfabetos volvieron a sufragar en 1988; en el Perú, en 1979. 
sucesivas y graduales ampliaciones ${ }^{6}$. El paradigma evolutivo resulta muy poco aplicable a la América Latina del siglo XIX y hoy también está puesto en tela de juicio en el ámbito europeo, pero de todas maneras sobrevive la idea de una ciudadanía política cuya expansión tendría que responder a los procesos de modernización ${ }^{7}$. A finales del siglo, el Perú estaba superando la dramática crisis causada por la derrota padecida en la guerra del Pacífico (1879-1883) y por la sucesiva oleada de conflictos internos, y se encaminaba hacia una fase de mayor estabilidad y transformaciones sociales (la definida por Jorge Basadre como la "república aristocrática"), en la que se formaría también en el país andino la "gran ilusión"8 oligárquica de un crecimiento indefinido. Sin embargo, a pesar de estar en una fase que reunía las características de la modernización, el primer y más evidente resultado de la reforma de 1895 fue la fuerte disminución del electorado, consecuencia del hecho de que, según los datos proporcionados por el censo de 1876 (el único de carácter nacional llevado a cabo en el siglo XIX), los analfabetos constituían el $84,4 \%$ de la población total (2.699.106 habitantes) y alrededor del $80 \%$ de los individuos de sexo masculino (que eran 1.360 .863$)^{9}$.

En el contexto peruano, caracterizado por una fuerte presencia de indígenas (el $57,59 \%$ del total de los habitantes y el 56,80\% de los hombres), la introducción de la alfabetización como único requisito exigido para el ejercicio del sufragio asumió una connotación de discriminación tendencialmente étnica, confirmada por el hecho de que en el curso de los debates que precedieron a la aprobación de la reforma en cuestión, casi constante fue la identificación entre analfabeto e indio. Aunque ni las cifras presentadas, ni las categorías de clasificación usadas, ni la manera en la

6 Me refiero, por supuesto, a estudios como los de Rokkan, según el cual la evolución occidental hacia una democracia electiva igualitaria puede ser analizada adecuadamente, haciendo referencia a un modelo ideal-típico en cinco fases, caracterizadas por la gradual ampliación del derecho a sufragio, la progresiva estandarización de los procedimientos y el mejoramiento de la relación votantes-representantes, gracias a los mecanismos proporcionales. Véase Stein Rokkan, Cittadini, elezioni, partiti, Bologna, Il Mulino, 1982 [1970], 232-233. La idea de la ciudadanía como proceso de evolución lineal aparecía ya en la conocida tríada marshalliana de los derechos civiles, políticos y sociales, cuya introducción caracterizaría respectivamente a los siglos XVIII, XIX y XX. Véase Thomas Humphrey Marshall, Citizenship and Social Class, London-Concord, Pluto Press, 1992 [1950], 1-51. Una síntesis de las críticas al 'optimismo marshalliano' y a su secuencia evolutiva puede encontrarse en Danilo Zolo, "La strategia della cittadinanza", en Danilo Zolo (ed.), La cittadinanza. Appartenenza, identità, diritti, Roma-Bari, Laterza, 1999, 3-91; y en Silvio Lanaro, "La cittadinanza tra semantica e storia", en Carlotta Sorba (ed.), Cittadinanza. Individui, diritti sociali, collettività nella storia contemporanea, Roma, Ministero per i beni e le attività culturali, Direzione generale per gli archivi, 2002, 3-11.

7 Acerca de esto, véanse las reflexiones desarrolladas por Raffaele Romanelli, "Una lettura storica della cittadinanza politica", en Antonio Annino y Maurice Aymard (ed.), Le cittadinanze di fine secolo in Europa e America Latina, Soveria Mannelli, Rubbettino Editore, 1996, 67-74, y con respecto al contexto latinoamericano, Antonio Annino, "La lunga linea grigia", en ibid., 29-55.

8 Aludo al título del libro de Marcello Carmagnani, La grande illusione delle oligarchie. Stato e società in America Latina (1850-1930), Torino, Loescher editore, 1981.

9 Según el censo, existía también un $2,02 \%$ de la población (equivalente al $2,15 \%$ de los individuos de sexo masculino) que solo sabía leer y un $13,5 \%$ (18,18\% de los hombres) que solo sabía escribir. Véase Censo general de la República del Perú formado en 1876, Lima, Imprenta del Teatro, 1878, tomo VII, “Apéndice”, 50. El censo aclara también que los hombres de más 21 años (que podían sufragar) eran 700.188 (el $51,45 \%$ del total de los hombres), pero como no proporciona datos de analfabetismo desagregados por fajas de edad, es imposible ser más minucioso en la información relativa a los hombres adultos que sabían leer y escribir. Ibid., 48. 
que los datos fueron recogidos se pueden considerar del todo fiables, queda claro que existía un porcentaje de iletrados que no eran indios, mientras que había indígenas que sabían leer y escribir. Sin embargo, la actitud de la mayoría de los legisladores de la época queda bien representada por las palabras pronunciadas por Manuel A. Bejarano, senador del departamento de Puno: aunque era contrario a la reforma, este afirmaba que "si la disposición rijiera solamente para las poblaciones indígenas del Sur de la República, sería aceptable, porque verdaderamente tenemos allí masas de pueblo inconsciente" 10 . Y continuaba:

"pero cuando veo que, felizmente, en el Perú los individuos que, aun cuando no saben leer y escribir, tienen perfecto criterio para determinar de los intereses del País, creo que sería arrebatarles una franquicia que no hay derecho para quitársela, bajo ningún aspecto, desde que todos formamos una comunidad política"11.

Para Bejarano, no saber leer ni escribir no era entonces en sí una causa total de incapacidad para entender, aunque para gran parte de la población indígena el analfabetismo derivaba en dicha incapacidad.

No obstante, las razones de la reforma no se atienen solo a esto. Para entenderlas del todo, es necesario indagar en las consecuencias de la temprana introducción del sufragio amplio e indirecto -establecido después de la Independencia debido al influjo ejercido por la constitución de Cádiz- y los problemas que había creado en el proceso de construcción de la representación. Asimismo, debemos preguntarnos por qué motivos el ejercicio de la ciudadanía política por parte de la población indígena resultaba incompatible con el proyecto de nación propuesto por las élites peruanas de finales del siglo XIX, hasta el punto de llevarles a dibujar de nuevo todo el espacio público.

\section{HASTA 1895: UNA CIUDADANÍA AMPLIA E INCLUYENTE, CON SUFRAGIO INDIRECTO}

En su versión original, la Constitución de 1860, todavía en vigencia a fines del siglo, afirmaba que "ciudadanos en ejercicio" eran los peruanos mayores de 21 años o casados, aun si no llegaban a esa edad (art. 37); el artículo siguiente establecía que del derecho a sufragio gozaban todos los ciudadanos que "saben leer y escribir, ó son jefes de taller, ó tienen alguna propiedad raíz, ó pagan al Tesoro público alguna contribución”. A tales condiciones, la ley electoral de 1861 (art. 1) añadía la de estar inscrito en el registro cívico del lugar de residencia ${ }^{12}$.

10 En los departamentos andinos meridionales de Puno y el Cuzco, la población india llegaba al $92,18 \%$, en el primer caso, y al 75,25\% en el segundo, mientras que en Ayacucho, Huancavelica y Junín dicha población era, respectivamente, el 72,30\%, 78,51\% y $61,72 \%$ del total. Véase Censo general, tomo VII, “Apéndice”, op . cit., 6-7.

11 Congreso Ordinario de 1895, Diario de los Debates de la H. Cámara de Senadores, Lima, Imprenta de "El País", 1895, 445.

12 El texto de la ley puede consultarse en La Constitución del Perú. Leyes y resoluciones dictadas por los Congresos de 1868-1870-1872-1873. Leyes orgánicas y reglamentos generales, Lima, Imprenta del Estado, 1873, 288-313. 
En aquel entonces, la república tenía casi cuarenta años y, sin embargo, el texto aprobado en 1860 constituía el punto de llegada de un recorrido largo y complejo: desde la Independencia, jurada en Lima en 1821, se habían promulgado seis constituciones y ocho textos entre leyes y reglamentos electorales, sin tomar en cuenta los del Protectorado de José de San Martín y los de la época de la Confederación PerúBoliviana. Se trataba, en el caso de las constituciones, de textos de carácter diferente, de inspiración liberal unos, conservadora los otros. Pero, con la única excepción de la Constitución Bolivariana (que solo estuvo vigente unos pocos meses), la cual puso entre los requisitos la alfabetización -exigida de manera inmediata-, todas establecieron un perfil de ciudadano con derechos políticos no censitario, no monoétnico y ampliamente incluyente, definido sobre la base de criterios más cualitativos que cuantitativos. El control de estos criterios se encargaba a las comunidades locales ( $\sin$ ninguna intervención de funcionarios del Estado), cuyas autoridades electivas elaboraban el registro cívico. La formulación de este perfil cambió indudablemente a lo largo de los años, volviéndose cada vez más precisa y articulada; no obstante, con la única excepción de la edad de los solteros, ningún requisito estableció elementos de cuantificación: ni siquiera la condición de contribuyente, introducida en 1834, estuvo acompañada por elementos que permitieran una cuantificación precisa. La alfabetización fue establecida como requisito por los textos de 1823 y 1839; sin embargo, ellos señalaron que en el caso de los indígenas y mestizos residentes en pueblos sin escuelas de educación básica, ese requisito no sería exigido efectivamente hasta 1840 (Constitución de 1823, art. 17, 3²) o 1844 (Constitución de 1839, art. $\left.8,2^{\circ}\right)$. Luego de este último año se dieron varias prórrogas $\mathrm{y}$, finalmente, un decreto de 1847 mantuvo el derecho a voto de indígenas y mestizos analfabetos, postergando la solución definitiva de la cuestión al momento en que se volviera a poner en debate el relativo artículo constitucional. Y esto acaeció en 1856, con la promulgación de una nueva Constitución que, anticipando la formulación propuesta más tarde por el texto de 1860 , consideró el ser alfabetizado como una de las posibles condiciones para acceder al sufragio.

En resumen, la figura del ciudadano titular del derecho de sufragio, tal como emerge de las normas de todo el siglo, acabó reproduciendo, aunque de manera más articulada, el modelo gaditano de un sujeto que podía mostrar un 'modo de vivir conocido', lo que remitía a su vez al 'vecino' de la tradición hispánica. Este se caracterizaba esencialmente por la autonomía económica y el reconocimiento social, para cuya identificación seguía siendo decisivo el criterio de notoriedad y el hecho de pertenecer a una comunidad local, confirmado por los notables de la misma.

La elaboración del registro cívico, en el cual tenían que aparecer los nombres de los habilitados para sufragar, fue siempre confiada a las municipalidades o, en los períodos en que fueron abolidas o su número fue limitado (por las constituciones de 1834 y 1839, y después por la de 1860) ${ }^{13}$, a juntas específicamente consti-

13 Una descripción de las leyes relativas a las municipalidades, desde la Constitución de Cádiz hasta 1861, puede encontrarse en Gabriella Chiaramonti, "De marchas y contramarchas: apuntes sobre la institución municipal en el Perú (1812-1861)", en Araucaria. Revista Iberoamericana de Filosofía, Política y Humanidades 18, Sevilla, 2007, 150-179. 
tuidas $^{14}$. Estas juntas actuaban por lo general en las parroquias-distritos, las unidades territoriales de base del proceso electoral indirecto de dos niveles, adoptado en todo el siglo hasta 1896, con la única excepción de los años comprendidos entre 1855 y $1860^{15}$. Por lo tanto, no era el Estado el que construía y definía la ciudadanía, sino las comunidades locales, las únicas capaces de establecer quién era vecino y quién no; de esta manera, dichas comunidades asumían una gran relevancia política, siendo la fuente de derechos constitucionales.

La competencia en materia de definición de la ciudadanía política fue defendida siempre con fuerza por las comunidades locales. En 1894, por ejemplo, se intentó implementar una nueva ley de registro cívico, aprobada el año anterior, que confiaba la elaboración de las listas electorales a delegaciones de distrito y de provincia, nombradas por una Junta Central del Registro Electoral ${ }^{16}$; no obstante, las protestas de los vecinos de muchos pueblos y distritos en contra de una ley definida como "descabellada", una "burla sangrienta", "atentatoria al sufragio popular",

14 La juntas estaban compuestas por jueces de paz, síndicos procuradores, notables y vecinos designados de entre los mayores contribuyentes, además del párroco o su sustituto y a veces el gobernador. Para un análisis de las normas relativas a la elaboración de los registros cívicos en las primeras décadas republicanas, véase Chiaramonti, Ciudadanía y representación, op. cit., 262-270. La presencia del gobernador, teóricamente un representante del gobierno, no debe engañar, pues en realidad también él era miembro a pleno título del grupo de notables locales. Nombrado generalmente por el prefecto tras propuesta del subprefecto, no remunerado o retribuido a veces con un porcentaje de los impuestos que debía recaudar, justamente por estas competencias en materia fiscal debía ser un personaje conocido y aceptado; no es casual que, según unas leyes, la persona que quisiera ocupar este cargo debía haber nacido en el distrito o haber residido en él por lo menos por cinco años. Véase el art. 137 de la Constitución de 1839 y el art. 29 de la "Ley 21 de Diciembre de 1849. Ley de funcionarios políticos", en Juan Oviedo, Colección de Leyes, Decretos y Órdenes publicadas en el Perú desde el año de 1821 hasta 31 de diciembre de 1859, tomo II, Lima, Felipe Bailly editor, 1861, 316. La Constitución de 1856 (art. 101) establecía que los gobernadores debían ser nombrados por los prefectos, tras propuesta de una terna de nombres hecha por las municipalidades locales. La Constitución de 1860 (art. 115) también encargaba a los prefectos el nombramiento de los gobernadores, pero la terna de nombres debía ser propuesta por los subprefectos.

15 Las parroquias, en teoría, desaparecieron como organismos administrativos a partir de la Constitución de 1828. No obstante, existieron durante todo el siglo como circunscripciones electorales básicas, incluso cuando los distritos se sobrepusieron a ellas. En cuanto al sufragio directo, este fue introducido por un decreto del mes de febrero de 1855 y confirmado sucesivamente por la Constitución de 1856 (art. 37) y la ley electoral aprobada en 1857 por la Convención Nacional.

16 La Junta Central estaba integrada por los presidentes de la Cámara de Diputados y de la de Senadores, por dos senadores y dos diputados designados por sus pares, y por dos "ciudadanos notables' elegidos por los anteriores (art. 2 de la "Ley de Registro Cívico", en Perú. Congreso, Cuadro de los electores de la República aprobado por el Congreso de 1893. Ley de registro cívico, Lima, Imprenta de la H. Cámara de Diputados, 1893, 45-49:45). Ya en 1874, durante el gobierno de Manuel Pardo, había empezado a debatirse un proyecto de ley de censo, registro cívico y elecciones, que proponía la creación en las capitales de provincia de juntas compuestas por "funcionarios responsables", "permanentes y rentados", los cuales tendrían el encargo de elaborar, tanto el censo de la población como el registro cívico. Pero la oposición de muchos parlamentarios en contra de un proyecto definido como "esencialmente centralizador", capaz de poner "trabas [...] al libre ejercicio del sufragio", sumada a la urgencia de debatir otras cuestiones más apremiantes (de carácter fiscal), bloquearon su camino. El texto del proyecto se encuentra en Congreso Ordinario de 1874, Diario de los Debates de la Cámara de Diputados, Lima, Imprenta "El Nacional", 1874, 311-322; para las citas, véanse las páginas 384 y 485 . Un análisis más detallado de este debate y del proyecto mismo se encuentra en Gabriella Chiaramonti, "Los nudos del sufragio: un problema de gobernabilidad republicana”, en Carmen McEvoy (ed.), La experiencia burguesa en el Perú (1840-1940), Frankfurt-Madrid, Vervuert-Iberoamericana, 2004, 285-307: 299-304. 
fueron tan difundidas y violentas, que resultó imposible realizar las elecciones previstas y la ley no fue aplicada ${ }^{17}$.

Volviendo a los requisitos que definían el perfil del ciudadano-elector, su amplitud, escasa precisión y naturaleza 'municipal' (por ser las comunidades locales las que se encargaban de su reconocimiento) originaron que, por lo menos formalmente, una parte importante de la población accediera al sufragio, incluso los indígenas de pueblos y comunidades, quienes podían ser considerados como contribuyentes o propietarios.

La contribución indígena, versión republicana del antiguo tributo colonial, introducida después del fracaso de los intentos bolivarianos de crear una fiscalidad nueva, sobrevivió hasta 1854 y constituyó una parte importante, si no decisiva, de los ingresos del Estado ${ }^{18}$.

Entre 1824 y 1825, unos decretos de Bolívar trataron de llevar a cabo la venta de las tierras de propiedad del Estado y la repartición en lotes individuales de las tierras de las comunidades indígenas. La gran cantidad de conflictos y protestas que debió suscitar la puesta en marcha de estas medidas, que amenazaban con la desarticulación de toda la sociedad indígena y de sus jerarquías internas, aparece reflejada en una serie de circulares enviadas a los prefectos, las cuales aclaraban que, en cualquier caso, se debía respetar "religiosamente la posesión actual en que se hallen los Peruanos"19, y en la decisión del Congreso Constituyente de 1827 ,

17 Para las citas, véase Biblioteca Nacional del Perú, Sala de Investigaciones (en adelante BNP, SI), D4786, Oficio dirigido por el Prefecto del Departamento de Ayacucho al Director General de Gobierno adjuntándole los documentos comprobatorios del no funcionamiento del Registro Cívico hasta mediados de enero del año en curso, Ayacucho, Febrero 5 de 1894; BNP, SI, D4825, Oficio cursado por el Prefecto del Departamento de Áncash al Director de Gobierno adjuntándole una representación de los vecinos de la ciudad de Huaraz relativo al funcionamiento de la Delegación del Registro Cívico, Huaraz, Enero 8 de 1894; BNP, SI, D7146, Expediente sobre la consulta formulada por el Prefecto del departamento de Puno, acerca de la forma de allanar la dificultad que presenta la falta de Juntas de Registro Cívico, Puno, Enero 11 de 1894. Muchos otros documentos que refieren las quejas suscitadas por la nueva ley se encuentran en la Colección de manuscritos de la Biblioteca Nacional del Perú; véanse, por ejemplo, los manuscritos que llevan los códigos D4764 (Paucartambo), D4966 (Cajamarca), D5281 (Cuzco) y D5321 (Lambayeque).

18 Acerca de la política fiscal de comienzos de la república y de los intentos de Bolívar de reformarla, véase María Isabel Remy, "La sociedad local al inicio de la república. Cusco, 1824-1850", en Revista Andina 12:2, Cuzco, 1988, 451-484: 460-469, y Víctor Peralta Ruiz, En pos del tributo. Burocracia estatal, elite regional y comunidades indígenas en el Cusco rural (1826-1854), Cuzco, Centro de Estudios Regionales Andinos Bartolomé de las Casas, 1991. En 1849, las contribuciones directas representaban el $27,9 \%$ de los ingresos totales, y de este porcentaje el $85 \%$ estaba representado por la contribución indígena, la mitad de la cual procedía de los tres departamentos andinos de Cuzco, Puno y Ayacucho (Remy, op. cit., 454, 457 y ss.). Carlos Contreras pretende desmentir la "imagen tan divulgada y bienintencionada, pero falsa, que eran los indígenas quienes mediantes su tributo sostenían principalmente los gastos del Estado"; no obstante, los datos que presenta confirman el hecho de que las contribuciones indígenas constituían la mayor parte de las contribuciones directas. Carlos Contreras, "Modernizarse o descentralizar: la difícil disyuntiva de las finanzas peruanas durante la era del guano", en Bulletin de l'Institut Français d'Études Andines 25:1, Lima, 1996, 125-150: 139.

19 Así eran llamados con frecuencia los indígenas, desde que un decreto de San Martín estableciera que quienes habían sido definidos en el pasado como "Indios ó Naturales" eran en realidad "hijos y ciudadanos del Perú" y, por lo tanto, debían recibir el nombre de "Peruanos". Véase el art. 4 del "Decreto supremo del 27 de agosto de 1821", en P. Emilio Dancuart, Anales de la Hacienda Pública del Perú. Historia y Legislación fiscal de la República, tomo I, Lima, Librería e Imprenta Gil, 1905, 237. 
que dictaminó suspender "por ahora" la venta de tierras de comunidad. En 1828, finalmente, una nueva ley reconoció a indígenas y mestizos la propiedad de las tierras ocupadas "sin contradicción", autorizándolos a venderlas si sabían leer y escribir $^{20}$

Sin embargo, aun esa ley tuvo pocas consecuencias prácticas. Cuando la contribución indígena fue abolida, surgieron dudas a propósito de si los indios podían ser considerados como propietarios de tierras de las que en realidad eran usufructuarios, y si, por lo tanto, los indígenas analfabetos podían ejercer el derecho de sufragio ahora que ya no eran contribuyentes ${ }^{21}$. Al alcalde del Cuzco, que pedía aclaraciones, el fiscal de la nación, José Simeón Tejeda, contestó que sin duda alguna la ley de 1828 había reconocido a los indígenas como propietarios de sus tierras. En consecuencia, los indígenas analfabetos de comunidades y pueblos pudieron seguir votando, y lo hicieron con razones mayores cuando, en 1867, fue introducida una contribución personal que les devolvió la calidad de contribuyentes $^{22}$. Por lo menos hasta la mitad del siglo existieron también normas que permitían a los indígenas analfabetos ser elegidos en el ámbito parroquial, o sea en el primero de los dos niveles previstos por el sistema electoral indirecto ${ }^{23}$.

Por supuesto, la amplitud del sufragio encontraba sus límites en el sistema indirecto de dos grados -en vigencia durante todo el siglo, con la única excepción, como se dijo anteriormente, de los años comprendidos entre 1855 y 1860 - y en los requisitos que debían tener los elegibles. El proceso previsto por la ley de 1861 (que en muchos aspectos repetía lo establecido por las anteriores) era relativamente sencillo: en mesas momentáneas, los sufragantes de cada parroquia elegían a los miembros de una mesa permanente, en la cual votaban al día siguiente para elegir electores de segundo grado en número proporcional a los habitantes. En un segun-

20 Se trató, como dice Jacobsen, de un compromiso pragmático entre la visión liberal (teóricamente compartida por los gobernantes peruanos) y la aceptación de la realidad corporativa del mundo indígena. Véase Nils Jacobsen, "Liberalism and Indian Communities in Peru, 1821-1920", en Robert H. Jackson (ed.), Liberals, the Church and Indian Peasants, Albuquerque, University of New Mexico Press, 1997, 123-170: 132 .

21 La ley electoral de 1857 (art. 2) establecía cuatro posibilidades: podían sufragar los que sabían leer y escribir, eran "jefes de taller”, tenían una propiedad raíz o "se habían retirado conforme á la ley, después de haber servido en el ejército ó armada".

22 Sobre la base del parecer de Tejeda, en febrero de 1859 se dictó una resolución que debía servir como norma general en situaciones parecidas. Véase Jorge Basadre, Historia de la República del Perú, 1822-1933, Lima, Editorial Universitaria, 1970, IV:376-377.

23 Las leyes de elecciones de 1828 y 1834 permitieron que, en los pueblos indígenas, un tercio de los electores de segundo grado, designados por las asambleas parroquiales, estuviera constituido por ciudadanos analfabetos, quienes podían ser acompañados por "adjuntos de su confianza", que escribieran en su lugar los votos, leyeran los documentos y firmaran las actas. En 1851 se estableció que se exentara de la obligación de saber leer y escribir a los electores indígenas que pagaban sus contribuciones. Véase "Ley 14 de Mayo de 1828. Reglamento de elecciones", arts. 31 y 41; "Ley 3 de Julio de 1834. Ley orgánica de elecciones", art. 20, en Oviedo, op. cit., I:341 y 361; "Ley 24 de Diciembre de 1851. Reglamento de elecciones", art. 27, $3^{\circ}$ (en ibid., II:31). En cuanto a las municipalidades, la ley de 1834, según la cual para acceder a los cargos municipales había que cumplir los mismos requisitos que se pedían para la elección a diputado, en el caso de los indígenas estableció que "vastará que paguen su contribución, o estén reservados de pagarla" (véase "Ley $1^{\circ}$ de Agosto de 1834. Ley orgánica de municipalidades", art. 8, en ibid., 381). 
do momento, los representantes de todas las parroquias de cada provincia, reunidos en el colegio electoral provincial, elegían a los miembros de la municipalidad de la capital de la provincia, al o los diputados de la provincia, al o los senadores del departamento al que pertenecía la provincia, y al presidente y a los dos vicepresidentes de la república. Con respecto a los requisitos de los elegibles, para ser elector de segundo grado, en general, era necesario ser vecino de la parroquia y saber leer y escribir ${ }^{24}$. Los requisitos se volvían más selectivos para los cargos superiores, es decir, miembros de las municipalidades, diputados y senadores, quienes debían tener cierto nivel de renta o una profesión que lo asegurara ${ }^{25}$.

Habiendo recibido el derecho a elegir y ser elegidos, por lo menos en el ámbito local, los indígenas lo utilizaron. La cuestión del sufragio de los indios indudablemente necesita de mayores investigaciones, como el análisis diacrónico de casos locales o, en lo posible, la lectura sistemática de registros y actas electorales de determinados años. Sin embargo, los elementos que emergen de estudios recientes, relativos al período de implementación de la Constitución de Cádiz y a las primeras décadas republicanas, llevan a cuestionar la idea, tan difundida en el pasado, de que los indígenas intervenían en las dinámicas electorales como figurantes o, en el mejor de los casos, como masa de presión violenta e inconsciente que votaba solo "nominalmente" -así lo señala Basadre ${ }^{26}$, o que simplemente no votaban. Por supuesto existieron manipulaciones y actos violentos, y es cierto que la población

24 Así lo establecía, por ejemplo, el art. 7 de la ley orgánica de elecciones de 1861.

25 Según la Constitución de 1860 , para ser diputado era necesario, además de tener 25 años (como mínimo), ser peruano de nacimiento, ciudadano en ejercicio, natural del departamento al que la provincia pertenecía o "tener en él tres años de residencia", tener una renta de 500 pesos o ser profesor de alguna ciencia; los senadores debían tener 35 años (como mínimo) y una renta de 1.000 pesos (arts. 47 y 49). La ley orgánica de municipalidades de 1861 (art. 37) establecía que los miembros de las municipalidades debían ser ciudadanos en ejercicio, vecinos de la provincia, de conducta irreprensible y tener una renta anual de 500 pesos en las capitales de departamento y de 300 en las capitales de provincia, renta que en ambos casos debía "provenir de bienes raíces, ó del ejercicio de cualquiera industria”.

26 Jorge Basadre, Elecciones y Centralismo en el Perú. Apuntes para un esquema histórico, Lima, Centro de Investigación de la Universidad del Pacífico, 1980, 53. Con respecto al período en que fue aplicada la Constitución de Cádiz en el virreinato del Perú, los documentos atestiguan la presencia de indígenas no solo como sufragantes, sino también como escrutadores y como 'compromisarios', es decir, los sujetos que, en el sistema electoral indirecto de cuatro grados establecido por aquel texto, eran elegidos por los ciudadanos con derecho a sufragio de cada parroquia y a su vez elegían a los electores parroquiales. Estos últimos, agrupados en juntas de partido, elegían a los miembros de la junta electoral provincial, la cual votaría a los diputados de las Cortes y al representante de esa intendencia en la diputación provincial (hay que recordar que, según la Constitución de Cádiz, la provincia era una circunscripción territorial muy amplia: la de Lima, por ejemplo, abarcaba las intendencias de Lima, Tarma, Trujillo, Arequipa, Huamanga y Huancavelica y las gobernaciones de Guayaquil y Chiloé con Valdivia). A las elecciones gaditanas en los pueblos andinos se refieren en particular los trabajos de (en orden cronológico) Christine Hünefeldt, "Los indios y la Constitución de Cádiz de 1812", en Allpanchis XI:11/12, Cuzco, 1978, 33-58; Nuria Sala i Vila, "La constitución de Cádiz y su impacto en el gobierno de las comunidades indígenas en el virreinato del Perú", en Boletín Americanista XXXIII:42-43, Barcelona, 1992, 51-70; Marie-Danielle Demélas-Bohy, "Modalidades y significación de elecciones generales en los pueblos andinos, 1813-1814", en Annino (coord.), Historia de las elecciones, op. cit., 291-313; Paniagua Corazao, op. cit.; Francisco Núñez, "La participación electoral indígena bajo la constitución de Cádiz (1812-1814)", en Aljovín de Losada y López (ed.), op. cit., 361-394; Chiaramonti, Ciudadanía y representación, op. cit., en particular el cap. II. 
indígena se encontraba en posición subalterna respecto de otros segmentos de la sociedad, especialmente en las áreas en que su presencia era más débil y donde más dominaba la hacienda ${ }^{27}$. No obstante, resulta inadecuada y reductiva la imagen de una sociedad indígena indiferenciada, pasiva y estática, que no debió corresponder a la realidad al menos durante una buena parte del siglo XIX. Al mismo tiempo, parece pertinente la observación de Annino, según la cual "practicar el voto no significa necesariamente aceptar su lógica institucional" 28 .

Para dar tan solo un ejemplo, eran indígenas al menos 30 de los 134 electores que componían el colegio electoral de la provincia de Quispicanchis (departamento del Cuzco), que se reunió en febrero de 1834 en Urcos (pueblo capital de la provincia). Los nombres aparecen minuciosamente transcritos en las actas; es posible que algunos de los apellidos indígenas (los varios Quispe, Condori, Illacambi, Ccaguaya, etc.) en realidad pertenezcan a mestizos, pero es todavía más probable que otros indios se oculten bajo apellidos aparentemente españoles. Esta presencia no debería sorprender, dada la composición étnica de la población: según datos de 1827, en la provincia de Quispicanchis los indígenas representaban el 87,7\% de los habitantes. Puede ser que los indios reunidos en Urcos no llegaran a entender cabalmente el significado de lo que debían hacer, o que no estuvieran interesados en el resultado final del proceso que los involucraba, pero desde luego eran muy conscientes de la necesidad y de la conveniencia de negociar su voto en favor de tal o cual sujeto, a cambio de la defensa de sus intereses y de los de la comunidad que los había elegido. Además, cabe destacar que estos indígenas formaban parte de un organismo que ejercía amplios y fuertes poderes (puesto que en aquel momento sesionaban nada menos que para elegir al Presidente de la República), y que su presencia significaba que ellos habían sido elegidos por su comunidad originaria como sus representantes y que, como tales, eran reconocidos por los demás miembros del colegio 29 .

A lo largo del siglo XIX, apellidos aparentemente indígenas continuarían apareciendo -por supuesto con mayor frecuencia en las provincias andinas- en los registros cívicos y en las actas electorales, ya fuera parroquiales (donde están registrados los nombres y apellidos de los sufragantes), ya fuera en las de los colegios electorales provinciales (donde solo aparecen los nombres de los electores de segundo grado). A pesar de que -como afirma Díez Hurtado- es más probable que hubiera indígenas con apellidos españoles que mestizos con apellidos indígenas, resulta complicado deducir conclusiones definitivas de ese tipo de documentos, en un período en el cual el mestizaje biológico y cultural ya estaba bastante difundido, aunque en medida diferente en las diversas áreas del país ${ }^{30}$.

27 Según el censo de 1876, una cuarta parte de la población rural vivía en haciendas. Véase Contreras, "Modernizarse o descentralizar", op. cit., 146.

28 Antonio Annino, "Introducción", en Annino (coord.), Historia de las elecciones, op. cit., 9-10.

29 BNP, SI, D1342, Actas de las elecciones realizadas en la provincia de Quispicanchis para el cargo de Presidente de la República, Urcos, Marzo $1^{\circ}$ de 1834.

30 Alejandro Díez Hurtado, que calcula, sobre la base de la lista de demandas presentadas, el porcentaje de población indígena que acudía a los jueces de paz (no disponiendo de más indicadores que los apellidos), concluye que la presencia de los indios tiende, en general, a ser subestimada por 
Entre los documentos electorales guardados en la Biblioteca Nacional del Perú (en Lima) y en el Archivo del Congreso de ese país, ha sido posible encontrar solo dos que ofrecen datos claros y detallados sobre la presencia de indígenas hábiles para sufragar: se trata de los registros de electores municipales de los distritos de Chuschi y Vischongo, en la provincia de Cangallo, departamento de Ayacucho, elaborados en $1893^{31}$. Ambos registros fueron redactados con unos criterios que definiría de anticuados, porque recuerdan de cerca los de décadas anteriores ${ }^{32}$. Los sujetos aparecen ordenados por orden alfabético, pero tomando en cuenta la letra inicial del nombre, no la del apellido. En la columna denominada "patria", mientras que en los otros registros presentes en el mismo legajo está escrito "Perú", en Chuschi se hace una diferenciación entre "español, vecino de Chuschi" y "natural de Chuschi" (o de otros pueblos y parcialidades del distrito), mientras que en el caso de Vischongo, los términos empleados son "blanco" y "peruano". Como es bien sabido, en 1821 San Martín promulgó un decreto que establecía que los indígenas, "hijos y ciudadanos del Perú", tenían que ser llamados "Peruanos"33. En una suerte de discriminación al revés, desde aquel momento y por mucho tiempo, aun en documentos oficiales y leyes, los indígenas fueron con frecuencia definidos como "peruanos", término que en algunas zonas del país acabó por ser utilizado para designar únicamente a los indios ${ }^{34}$. Es muy probable que la definición empleada en el registro de Vischongo remita a esa costumbre, hipótesis confirmada por el hecho de que los "peruanos" de Vischongo tienen en su gran mayoría apellidos indígenas (Quispe, Sulca, Paquiauri, Mallqui, Huaman, Atachaua, Vilcapoma, Auccapoma, Huamanchaua, Huamani, Yupanqui, Llantoy, Taguada, etc., los que se repiten muchas veces). En el caso de Cuschi, los "naturales” se apellidan Quispe, Collahuacho, De la Cruz, Yalli, Caico, Chipoma, Pacataipe, Promani y Chaupin.

los estudiosos. Véase Alejandro Díez Hurtado, Comunes y haciendas: Procesos de comunalización en la sierra de Piura, siglos XIX-XX, Piura/Cuzco, 1998, 163-168, citado en Nils Jacobsen y Alejandro Díez Hurtado, "Montoneras, la comuna de Chalaco y la revolución de Piérola: la sierra piurana entre el clientelismo y la sociedad civil, 1868-1895", en Antonio Escobar Ohmstede y Romana Falcón (coord.), Cuadernos de Historia Latinoamericana 10: Los ejes de la disputa. Movimientos sociales y actores colectivos en América Latina, siglo XIX, Madrid-Frankfurt am Main, 2002, 127. Sobre la dificultad de definir la pertenencia a los distintos grupos étnicos, debida al "aspecto relacional de la etnicidad", por el cual "una persona que era india en una determinada relación" podía "convertirse de mestiza en otra", véase Marisol de la Cadena, "Decencia y cultura política: Los indigenistas del Cuzco en los años veinte", en Revista Andina, 12:1, Cuzco, 1994, 79-118: 80.

31 BNP, SI, D5565, Duplicado del Registro de Electores municipales de los distritos de Vischongo, Totos, Chusqui [sic], Canaria, Colca, Paras, Huancarailla, y cercado de Cangallo. Ayacucho, Marzo 9 de 1893.

32 Para el análisis de varios registros cívicos de 1847, véase Chiaramonti, Ciudadanía y representación, op. cit., 270-276.

33 Véase nota 19.

34 El "Reglamento de elecciones municipales" de 1821 (en Oviedo, op. cit., I:308-313) prescribía que las elecciones debían celebrarse en Lima, en las capitales de la costa y de la sierra, en las villas y pueblos, y en los "pueblos de peruanos", es decir, en los que anteriormente recibían la denominación de "pueblos de indios". Mark Thurner refiere que, en la provincia de Huaylas, la definición de "peruanos" no se aplicaba a todos los ciudadanos, sino únicamente a los indios de comunidades, llamados también "ex-indios". Mark Thurner, From Two Republics to One Divided. Contradictions of Postcolonial Nationmaking in Andean Peru, Durham \& Londres, Duke University Press, 1997, 24. 
En ambos casos, queda pendiente el problema de dónde se ocultan los mestizos. Por cierto este problema -el de la 'invisibilidad' de los mestizos- existió por lo menos desde que la Constitución de Cádiz esbozó una ciudadanía única para todos (españoles, criollos, mestizos e indios). Hay que decir que, en el caso de nuestros dos distritos, la cuestión era probablemente marginal, porque, si nos atenemos al censo de 1876, no había mestizos en Vischongo y solo 6 en Chuschi ${ }^{35}$.

Según el mismo censo, en 1876 los dos distritos tenían respectivamente 558 y 1.260 habitantes hombres, de los cuales el $96 \%$ en Chuschi y el $88,5 \%$ en Vischongo eran clasificados como indios. En 1893 aparecen inscritos en el registro 18 sujetos en Chuschi (6 "españoles" y 12 "naturales") y 389 en Vischongo (148 "blancos" y 238 "peruanos"). Esta gran diferencia se explica por el hecho de que el 14 de octubre de 1892 se había promulgado una nueva ley de municipalidades, que por primera vez separaba las elecciones municipales de las políticas, y creaba un electorado municipal distinto del político. Según el art. 29, las elecciones municipales se practicaban por sufragio directo y del derecho de sufragio gozaban todos los vecinos, peruanos y extranjeros mayores de 21 años o casados, que, "á más de saber leer y escribir, ejerzan alguna profesión ó industria, ó tengan una propiedad raíz" ${ }^{36}$. Es muy probable que el registro de Chuschi, fechado el 28 de enero de 1893, haya sido redactado según las nuevas normas, mientras que el de Vischongo (del 20 de diciembre de 1892) siguiera todavía la ley anterior. Volviendo a los datos proporcionados por los dos registros, el de Vischongo nos dice además que el $80,3 \%$ de los ciudadanos inscritos era analfabeto $(65,5 \%$ de los "blancos" y $89 \%$ de los "peruanos") y que la profesión más difundida, como era de esperarse, era la de agricultor.

Indudablemente, la lectura de estos documentos suscita otras interrogantes: por ejemplo, cabe preguntarse si los registros habían sido manipulados y si los inscritos sufragaban de verdad. Sin embargo, y a pesar de todo, ellos permiten dar un paso adelante en el intento de efectuar un análisis sin prejuicios de la cuestión del sufragio indígena o, si se quiere, del interés de los indios respecto de los procesos electorales.

\section{LAS ELECCIONES EN LA SEGUNDA MITAD DEL SIGLO XIX: UN PROCESO INCONTROLABLE}

Sobre sufragio y leyes electorales se debatió en muchas oportunidades a lo largo del siglo, y en particular después de 1860, cuando la relativa estabilización de la situación política interna concedió una importancia creciente a las dinámicas electorales, como medio para adquirir y legitimar el poder. Objetos de debate y de condena fueron sobre todo los actos violentos e irregularidades que muchas veces

\footnotetext{
35 Censo general, op. cit., III, Departamentos de Ayacucho y Cajamarca, 30 y 69.

36 El artículo agregaba que "la ley reputa que no sabe escribir al que solo ha aprendido a firmar". Véase Legislación municipal. Leyes, resoluciones, decretos, ordenanzas y reglamentos vigentes sobre municipalidades: colección publicada por el H. Concejo provincial de Lima, Lima, 1899, 33-34.
} 
se producían en las jornadas electorales, y que no eran una prerrogativa exclusiva de ninguna de las facciones en lucha; las mismas denuncias de fraude estaban frecuentemente entre los recursos empleados por quien perdía para deslegitimar a los ganadores ${ }^{37}$.

Las causas de esos desórdenes, para muchos parlamentarios, eran la excesiva amplitud del sufragio y el sistema indirecto, al cual los constituyentes de 1860 habían regresado después de las negativas experiencias de los años anteriores. Había quien consideraba dicho sistema como inferior desde un punto de vista teórico, pues -afirmaba- no hacía sino abrir cómodos caminos al abuso; no obstante, la mayoría estaba convencida de que era necesario, considerando el gran número de ciudadanos, y entre ellos los indígenas, que tenían derecho al sufragio ${ }^{38}$.

Las argumentaciones desarrolladas en el curso de estos debates -sobre una parte de las cuales volveré más adelante- son desde luego bastante previsibles. En este punto me parece más útil detenerme a analizar unas cuestiones que emergieron en 1860 y 1862, cuyas implicancias son -en mi opinión-decisivas para entender las reformas aprobadas en los años noventa. Todas estas cuestiones remiten a un mismo problema central, referido a que no existía en el país una dimensión capaz y con voluntad de empadronar a la población, examinar su consistencia y su distribución y de controlar adecuadamente los procesos que se desarrollaban en el territorio nacional. Tal situación dejaba abierta la posibilidad de que, considerando los múltiples nexos que las leyes establecían entre el número de habitantes y los distintos momentos del proceso de construcción de la representación, este último pudiera ser distorsionado aun antes de la emisión del sufragio (por lo tanto, antes de que ocurrieran actos violentos e irregularidades) y fuera en realidad incontrolable desde el centro del sistema político.

Un primer problema surgió en diciembre de 1860, cuando, después de la promulgación de la Constitución, se estaba discutiendo la nueva ley de elecciones. En los años anteriores habían sido creadas muchas nuevas circunscripciones administrativas (distritos y provincias) $^{39}$. José Silva Santistevan, senador por Cajamarca, lamentó que a la provincia del mismo nombre -constituida oficialmente en el mes de septiembre de dicho año- se le hubiesen reconocido por error solo dos diputados, en lugar de

37 Refiriéndose al caso colombiano, Eduardo Posada-Carbó formula opiniones análogas. Véase "Fraude al sufragio: la reforma electoral en Colombia, 1830-1930", en Carlos Malamud (coord.), Legitimidad, representación y alternancia en España y América Latina: las reformas electorales (1880-1930), México D.F., Fideicomiso Historia de las Américas, 2000, 208-229.

38 Es oportuno subrayar el hecho de que, a pesar de las muchas y ásperas críticas formuladas en contra de las prácticas ilegales y violentas, el título de la ley electoral de 1861 (en vigencia de manera casi continua hasta las reformas de fines de siglo) que se refería a los "actos prohibidos en las elecciones" (el IX) era muy conciso, y las penas previstas, poco más que simbólicas. Por ejemplo, se sancionaba con 24 horas de detención a quien no respetara la prohibición de ingresar con armas al lugar donde se desarrollaban las votaciones (art. 78). Más severa era la ley hacia los funcionarios del gobierno (prefectos, subprefectos, gobernadores, tenientes gobernadores y agentes de policía), cuya entrada en el lugar de las elecciones quedaba prohibida y que, en caso de no obedecer, serían destituidos de sus empleos (art. 79).

39 Los datos relativos a distritos, provincias y departamentos, y a las fechas de su creación, se encuentran en Perú. Dirección de Estadística, Demarcación política del Perú, Lima, Imprenta del Estado, 1874, 249-267. 
los tres a los que tenía derecho sobre la base de un censo local efectuado en $1855^{40}$. El problema se hacía más serio porque -como lo denunciaba el senador- otras provincias, como las de Arequipa y Cuzco, habían conseguido aumentar su representación, mientras que en el caso de Cajamarca y también en el de Chota (perteneciente, asimismo, al departamento de Cajamarca), el Congreso se había atenido a datos demográficos anticuados. En conclusión, lo que pedía era "o el aumento para mi provincia, o la nivelación para todas" 41 . El Congreso solucionó momentáneamente el problema evitando introducir en el texto de la ley de elecciones el cuadro completo de los diputados que cada provincia podía elegir. Por lo tanto, y confiando en el hecho de que se estaba discutiendo también una ley de censo y registro cívico -que sería aprobada en 1861-, se limitó a establecer que la elección de diputados se realizaría "con arreglo [...] al plan que debe dar el Congreso de 1862, según el censo general que para entonces deberá estar concluido" (art. 44).

Pero otras cuestiones, aun más sorprendentes y preocupantes, salieron a flote precisamente en 1862. Mientras los parlamentarios se dedicaban a las calificaciones de los resultados de las elecciones que recién se habían realizado ${ }^{42}$, se dieron cuenta de que estaba aumentando rápidamente el número de los electores de segundo grado, los que componían los colegios electorales provinciales y que eran decisivos para los resultados finales de los procesos electorales. La discusión se suscitó a propósito de la provincia de Jauja ${ }^{43}$, cuyos electores habían subido de 176 en 1850 a 270 , lo que constituía una infracción de la ley electoral vigente (la de 1861), por la cual las parroquias, "mientras no esté formado el censo general de la República”, debían designar "el mismo número de electores que se nombró en el año de 1853" (art. 101). No se trataba de una situación aislada, porque enseguida salieron a la luz otros casos análogos, como los de Loreto y Luya. Pronto, uno de los partícipes del debate comunicó que en los periódicos de la capital habían

40 La Constitución recién aprobada establecía que se elegiría un diputado por cada 30.000 habitantes, o fracción que pasara de 15.000 , y por cada provincia, aunque su población no llegara a este número (art. 46); el artículo agregaba que "se fijará por una ley el número de diputados que, según este artículo, corresponda a cada provincia; y no podrá aumentarse sino por disposición previa del Congreso". Véase Ricardo Aranda, La Constitución del Perú de 1860 con sus reformas hasta 1915. Leyes orgánicas, decretos, reglamentos y resoluciones referentes a ella, Lima, Librería e Imprenta Gil, 1916, 11 y 12.

41 Diario de Debates del Congreso Ordinario del año de 1860, Lima, Tipografia del Comercio, $1861,270-272$.

42 A partir de 1839, las leyes electorales atribuyeron a las Cámaras el poder de dictaminar sobre la validez o invalidez de los procedimientos electorales, para evitar la interferencia en las elecciones de otros poderes, en especial del Ejecutivo. Las Cámaras, indudablemente, abusaron de este poder, pero afirmar que "tomaron la costumbre de incorporar a los partidarios de la mayoría dominante, así como la de descartar a los adversarios" (Basadre, Elecciones y Centralismo, op. cit., 31) implica una excesiva simplificación de las relaciones entre el Legislativo y el Ejecutivo, que a menudo eran muy conflictivas, y transmite la imagen de un gobierno que siempre podía controlar los resultados de las elecciones. Ulrich Mücke, en cambio, afirma que en la segunda mitad del siglo XIX "no party and no president had the capacity to impose their decisions in congress". Ulrich Mücke, "Elections and Political Participation in Nineteenth-Century Peru: The 1871-72 Presidential Campaign", en Journal of Latin American Studies 33, Cambridge, 2001, 311-346: 337.

43 Congreso Ordinario del año de 1862, Diario de los Debates, Lima, Tipografía del Comercio, $1862,137 \mathrm{y}$ ss. 
aparecido datos de carácter nacional relativos a todas las provincias cuyas elecciones ya habían sido aprobadas. El resultado sorprendió a los mismos miembros del Congreso, porque lo que había pasado era que el número total de electores había subido de 3.804 que eran en 1853 a 4.699 en 1862, sin contar los de las provincias cuyas elecciones habían sido anuladas ${ }^{44}$.

La causa de este aumento estaba solo parcialmente en irregularidades; la verdad, la raíz del problema estaba en la ley de 1861 que, si por un lado había establecido que no se podían aumentar los electores de 1853 (art. 101) ${ }^{45}$, por otro, había atribuido al presidente de la mesa electoral permanente de cada parroquia (que era nada menos que uno de los notables locales) la tarea de decidir de modo incuestionable, teniendo en cuenta los datos del relativo censo, a cuántos electores debía designar su circunscripción (art. 14). Según el artículo 5, la proporción era de un elector por cada 500 habitantes o fracción que superase los 250, pero el artículo 6 agregaba que cada pueblo, "aunque tenga menos de 250 habitantes", debía nombrar un elector ${ }^{46}$.

No es fácil entender las razones que llevaron a la introducción de esta medida, que proponía una especie de 'sufragio corporativo': como dijo el senador Silva Santistevan, la ley "ha reconocido á cada pueblo como una entidad política y les ha concedido el derecho político de sufragar" ${ }^{47}$. Es muy probable que los legisladores no consideraran el criterio numérico ni adecuado ni suficiente para representar de manera satisfactoria un territorio complejo, de población bastante esparcida en centros de tamaño a veces muy reducido, que, sin embargo, en algún momento habían sido jurídicamente reconocidos como 'pueblos' (lo que formalmente solo el Congreso podía hacer); un territorio que seguía siendo en muchos sentidos muy tradicional y en el cual las circunscripciones se consideraban todavía como titulares de derechos antiguos, como el de gozar de cierto nivel de autonomía y de ser representados ante las instancias superiores. La medida podía ser tomada también como una suerte de compensación para los centros menores, que, habiendo sido privados por la ley de municipalidades de 1861 de la posibilidad de elegir organismos municipales autónomos, de esta forma veían al menos asegurada su posibilidad de participar con un representante propio en el colegio electoral provincial ${ }^{48}$.

$44 \quad$ Ibid., 136.

45 El texto de este artículo, comprendido entre las disposiciones transitorias, decía que "mientras no esté formado el censo general de la República se elegirá el mismo número de electores que se nombró en el año de 1853 ".

46 Anteriormente, constituciones y leyes se habían limitado a establecer una relación numérica entre habitantes y electores, que podía ser de un elector por cada 200 individuos (Constitución de 1823, art. 33; Constitución de 1828, art. 13, y Constitución de 1834, art. 13), de un elector por cada 100 ciudadanos (Constitución de 1826, art. 20), o de un elector por cada 500 individuos (reglamento de elecciones de 1839, art. 34). La ley de 1839 agregaba que "la parroquia que tenga ménos de quinientas almas dará siempre un elector" (art. 34), introduciendo un mecanismo parecido a la representación de los pueblos de la ley de 1861.

47 Congreso Ordinario del año de 1862, Diario de los Debates, op . cit., 557.

48 Según la ley de 1856 (en Oviedo, op. cit., II:409) debían elegirse organismos municipales en las capitales de departamentos, provincias y distritos y en núcleos que, sin ser capitales de distrito, tuvieran más de mil habitantes. Una segunda ley, también de 1856 (ibid., 423-429), enumeraba todos los lugares en donde tendrían que elegirse municipalidades, que eran 699. En cambio, la ley de 1861 
Finalmente, hay que tener también en cuenta el hecho de que el artículo 6 terminaba estableciendo que "las haciendas, parcialidades y pagos se reunirán al pueblo de que dependen", lo que introducía un ulterior elemento de arbitrariedad y de fluidez, haciendo de un pueblo una entidad de confines y población inciertos y fluctuantes, demográficamente incontrolable, puesto que las agrupaciones menores podían decidir unirse en determinado momento a un pueblo y luego a otro, según sus necesidades y conveniencias ${ }^{49}$.

Para tratar de solucionar los problemas que causaban las contradicciones de las normas vigentes y limitar el poder sumamente discrecional que estas otorgaban a los presidentes de las mesas, los parlamentarios se apresuraron a dar una nueva ley, por la cual en adelante sería el Congreso el que, en vista de los resultados del censo, fijaría el número de electores que cada provincia podía designar; mientras tanto -repitiendo con mayor fuerza lo que ya había dicho la ley de 1861 en sus disposiciones transitorias- las parroquias no podían aumentar "bajo pena de nulidad, el número de electores que se hallaban en posesión de dar en el año de $1853 " 50$, fecha a la cual remontaba "el único [registro] oficial que tenemos" 51 . Las nuevas disposiciones, sin embargo, volvían a poner sobre el tapete un viejo problema, al interior de un círculo vicioso que parecía no tener salida. De hecho, en 1851 había pasado algo parecido: el reglamento electoral de aquel año encargó al gobierno la aprobación del censo y la declaración del número de electores de cada provincia; pero, como se calculó que los resultados del censo no se conseguirían en un tiempo útil, un decreto posterior terminó estableciendo que en cada parroquia se nombraría "el mismo número de electores que tuvieron los anteriores colegios" 52 .

Como ya se ha dicho, en 1861 se dictó una ley de censo y registro cívico y las operaciones avanzaron, aunque de manera desigual en las distintas áreas del país, puesto que todas las operaciones, desde el levantamiento de los datos hasta su

establecía que se elegirían municipalidades únicamente en las capitales de departamentos y de provincias y en los centros urbanos calificados como 'ciudades', mientras que en las capitales de distrito se podían elegir solo agencias municipales, dependientes de la municipalidad respectiva. Véase los artículos 2, 3, 4, 6 y 7 de la "Ley orgánica de municipalidades", en La Constitución y leyes orgánicas del Perú dadas por el Congreso de 1860, comparadas con las que sancionó la Convención Nacional de 1855, Lima, Imprenta del "Mercurio", 1862, 159-187.

49 Escribía Mateo Felipe Paz-Soldán que "hay pueblos que apenas tiene veinte casuchas y sus pobladores no llegan a cincuenta [...]. También es frecuente que aunque el titulado pueblo es pequeño y miserable, está rodeado de aldeas, llamadas parcialidades, estancias, etc. y estas suman una población más o menos numerosa". Mateo Felipe Paz-Soldán, Diccionario geográfico-estadístico del Perú, Lima, Imprenta del Estado, 1877, XV.

50 Art. 4 de la "Ley 3 de Diciembre de 1862", en La Constitución del Perú. Leyes y resoluciones, op. cit., 321 .

51 Diario de Debates del Congreso Ordinario de 1860, op cit., 272. En realidad no se trataba de un censo, sino de datos deducidos de las matrículas de contribuyentes, como afirman explícitamente las notas al pie de página de los cuadros generales publicados en El Peruano en mayo de 1850. Véanse "Censo de almas de la República" y "Censo rectificado de la República", aparecidos en El Peruano, el 1 y 4 de mayo de 1850 y recopilados en ibid., 141 y 144 respectivamente.

De la escasa fiabilidad de tales datos eran conscientes los mismos miembros del Congreso de 1860, al afirmar que "la república se halla sin matrícula desde el año de 1848 [...]; desde que se suprimió la contribución de indígenas, ya no hay revisitas". Véase ibid., 997.

52 "Ley 24 de Diciembre de 1851. Reglamento de elecciones" y "Decreto de 5 de Enero de 1852. Sobre reunión y renovación de los colegios electorales”, en Oviedo, op. cit., II:29-30 y 38. 
recopilación, se encargaron a 'comisionados' nombrados por los prefectos, uno por cada provincia, que actuaban cada uno por su cuenta, sin la menor coordinación ${ }^{53}$. En realidad, al no haber criterios homogéneos, no se trató de un censo nacional, sino de múltiples censos locales. Sin embargo, aun con sus límites, los datos así recogidos podían ser más exactos; no obstante, los resultados de la operación tardaban en conocerse y por esta razón se decidió emplear todavía los de 1853.

En el debate que en 1861 precedió a la aprobación de la ley de censo, emergió un segundo problema: el recuento de la población se estaba haciendo por distritos y, en consecuencia, aun cuando estuvieran disponibles sus resultados, al Congreso le sería muy difícil determinar el número exacto de electores de segundo grado, puesto que dicho censo no contemplaba el número de los pueblos. Fue una vez más el senador por Cajamarca, José Silva Santistevan, quien planteó el problema; para que la cuestión resultara más clara, el senador Manuel Antonio Chávez propuso el ejemplo de la provincia de Canta, a la cual el reciente censo atribuía 19.000 habitantes, razón por la que el Congreso había decidido que le correspondían 38 electores. Sin embargo, en dicha provincia había 54 pueblos, cada uno de los cuales, según el artículo 6 de la ley de elecciones, tenía derecho de designar a un elector de segundo grado. Por lo tanto, Canta debía elegir no 38 sino 54 electores, que "vendrán al Congreso con las actas electorales, actas que no podrán ser anuladas en virtud de que estarán favorecidas por la disposición de la ley"54.

La cuestión era verdaderamente difícil de solucionar. En 1862 fue formada una comisión encargada de formular un proyecto de ley de demarcación territorial, pero sus miembros declararon que dicha tarea no podía llevarse a cabo, dada la falta de datos fiables y la escasa buena disposición de las autoridades, tanto centrales como periféricas, a las que se habían dirigido para obtener informaciones adecuadas $^{55}$. Otra comisión especial fue formada posteriormente, con el encargo esta vez de redactar el cuadro de los electores de segundo grado que, según los datos finalmente disponibles del censo de 1862, cada provincia tenía que elegir. No obstante, en enero de 1865 sus miembros comunicaron "con sentimiento" a los diputados que no habían podido cumplir su cometido, pues los datos que recibieron habían sido recogidos por distritos y no por pueblos. Contar el número de pueblos que componían las 83 provincias del país -afirmaban- era una tarea demasiado ardua para poderla efectuar en el poco tiempo que faltaba para la conclusión de la legislatura. La comisión finalmente hizo una propuesta, que no llegó a ser discutida, según la cual la única solución era constituir una junta en cada capital provin-

53 Los comisionados debían actuar en colaboración con gobernadores, párrocos, síndicos o "individuos notables" de cada pueblo. Una vez completado el censo de cada provincia, la municipalidad respectiva tenía que examinarlo y luego pasarlo al prefecto, que tenía que aprobarlo o bien ordenar eventuales modificaciones. Los cuadernos originales de cada distrito debían ser conservados por los gobernadores, puesto que a partir de ellos se redactaría el registro cívico. Véase la "Ley de censo y registro cívico", en Ricardo Aranda, La constitución del Perú de 1860 con sus reformas hasta 1893. Leyes orgánicas, decretos, reglamentos y resoluciones referentes a ellas, Lima, Imprenta de la $\mathrm{H}$. Cámara de Diputados, 1893, 389-394.

54 Congreso Ordinario del año de 1862, Diario de los Debates, op. cit., 547.

55 Ibid., 132-133. 
cial, compuesta por las autoridades locales, que contara habitantes y pueblos y, por fin, estableciera el número de los electores correspondientes ${ }^{56}$.

En 1876, durante la presidencia de Manuel Pardo, se hizo otro censo. Fue utilizada la ley de 1861, pero introduciendo unas novedades muy importantes: el censo fue efectuado por personal nombrado ad hoc por el gobierno y organizado por una institución específica, la Dirección de Estadística (creada en 1873). Asimismo, el gobierno central corrió con el sueldo del personal y lo dotó de instrucciones precisas y homogéneas y de poderes suficientes para obtener la efectiva colaboración de las autoridades políticas locales. Los datos se recopilaron en un período de tiempo razonablemente breve, con excepción de algunas localidades, y fueron reunidos en Lima, analizados y presentados -siguiendo criterios homogéneos- por el mismo personal que había participado en su recolección. Así, este comenzaba a disponer de una -aunque mínima- preparación específica ${ }^{57}$.

Aun con sus muchas limitaciones y defectos, el de 1876 fue el primer censo nacional digno de ese nombre realizado en la república (y también el último del siglo XIX, puesto que no se volvió a hacer otro de población hasta 1940). Lamentablemente dicho censo, cuyos resultados se publicaron en 1878, no llegó a ser aprobado por ambas Cámaras: en diciembre de ese año, los senadores aprobaron un proyecto de ley según el cual el censo de 1876 "servirá desde la fecha para todos los actos legales en relación con el cómputo de los habitantes" (art. 2) ) $^{58}$. El texto pasó a la Cámara, que comenzó a discutirlo, pero el debate se postergó, hasta que las apremiantes exigencias de la guerra con Chile lo cancelaron de la agenda de trabajos. Emblemáticas de los nuevos y dramáticos problemas que angustiaban a los gobernantes del Perú son las noventa y dos cajas de madera fabricadas expresamente para recoger los documentos del censo de cada provincia, que en junio de 1880, por orden del Secretario de Estado en el Departamento de Guerra, fueron adaptadas para servir como "botiquines para el ejército" 59.

Cuando -después de la guerra y la ocupación chilena y de las contiendas civiles que agobiaron al país durante buena parte de los años ochenta- se retomó una vida política regular, volvió a presentarse el problema de la correcta indicación del número de electores de segundo grado que se debía elegir. Sin embargo, como no había tiempo para realizar un nuevo censo y el de 1876 no solo no había sido aprobado por ambas Cámaras, sino que -se dijo- ya estaba desfasado, por los muchos años que habían transcurrido, un decreto del 14 de abril de 1895 ordenó

56 Archivo del Congreso del Perú (en adelante ACP), 1864-1865, legajo 4, Asuntos generales resueltos solo por la Cámara de Diputados, expediente 4, Electores de la República, Lima, Enero 7 de 1865 .

57 Sobre el censo de 1876 y sus vinculaciones con las problemáticas electorales, véase Gabriella Chiaramonti, "Buscando al ciudadano 'virtuoso'. El censo peruano de 1876 en el proyecto político de Manuel Pardo", en Marcello Carmagnani (coord.), Constitucionalismo y orden liberal. América Latina, 1850-1920, Torino, Otto editore, 2000, 9-50.

58 ACP, 1879/3, Asuntos generales pendientes en varias comisiones/Gobierno/legajo 4, Lima, Diciembre 13 de 1878, que contiene el Proyecto de ley aprobado por la H. Cámara de Senadores, aprobando el Censo General de la República, levantado el año de 1876.

59 Archivo General de la Nación, RJ 186, Oficio de Manuel M. Bravo, Director del Archivo Nacional del Perú al Sub Secretario de Instrucción, de fecha 10 de junio de 1880. 
que las elecciones del año siguiente se desarrollaran conforme a la ley electoral de 1861 y que se eligiera "en cada parroquia el número de electores que le corresponda conforme al censo de 1853" $"$. Sin embargo, el Cuadro de los electores de la República, aprobado por el Congreso de 1893, muestra que el número de los electores había seguido creciendo, muy probablemente debido a la presión de diversos representantes en el Congreso ${ }^{61}$.

\section{LA REPRESENTACIÓN DISTORSIONADA: LOS CUADRos DE MANUEl AtANASIO FuENTES}

Después de más de cuarenta años (y de dos censos, aunque defectuosos), la situación seguía siendo la misma. Lo que hacía falta no era solo la capacitad de contar correctamente la población y los pueblos, sino también -y quizás sobre todo- la voluntad política de dar solución a un problema cuya envergadura y naturaleza los legisladores tenían que conocer desde hacía varios años, pues sus consecuencias aparecían con toda evidencia en unos cuadros, adjuntados al proyecto de ley que en 1878 los diputados no habían llegado a aprobar ${ }^{62}$, que habían sido compilados por Manuel Atanasio Fuentes, jefe de la Dirección de Estadística desde $1877^{63}$.

Los cuadros contenían tres series de datos: la población de cada departamento, articulada por provincias y distritos; el número de electores que a partir de tales datos cada circunscripción debía elegir; y el número de los electores que en ese entonces elegía, según los informes que los subprefectos habían remitido a Fuentes (ver el Cuadro I, en el cual, en la columna D, aparecen también los datos del Cuadro de electores de 1893).

Tras analizar los datos de los cuadros, se llega a diversas conclusiones. En primer lugar resulta evidente que el mayor número de electores pertenecía a provincias y departamentos andinos, lo cual, si se toma en cuenta la amplitud del sufragio, no era sino la consecuencia necesaria de la distribución de la población y de la geografía del país. Considerando como andinos los departamentos de Cajamarca, Áncash (sin la provincia de Casma-Santa, situada en la costa), Huánuco, Junín, Huancavelica, Ayacucho, Arequipa (sin las provincias de Camaná, Castilla e

60 Artículos 3 y 4 del "Decreto de 14 de abril de 1895", en República del Perú. Ministerio de Gobierno y Policía, Leyes, Decretos y Resoluciones expedidas por el Ministerio de Gobierno y Policía desde el 20 de Marzo de 1895. Edición oficial, Lima, Imprenta La Industria, 1898, 39-41.

61 Perú. Congreso, Cuadro de los electores de la República, op. cit., 3-43.

62 La ley que los diputados no habían llegado a sancionar en 1878 proponía la aprobación no solo del censo, sino también de unos "cuadros de la estadística electoral [...] publicados por el Ministerio de Gobierno [...] con arreglo al resumen del censo general [...]" (art. 3). Véase Proyecto de ley aprobado por la H. Cámara de Senadores, aprobando el Censo General de la República, levantado el año de 1876, op. cit.

63 Ministerio de Gobierno. Dirección de Estadística, Estadística electoral y parlamentaria del Perú. 1870 a 1876, Lima, Imprenta del Teatro, 1878. En el ejemplar de esta obra que he podido revisar en la Biblioteca Nacional del Perú faltan los datos detallados relativos a los departamentos de Apurímac, Huancavelica, Huánuco y Piura. 
Islay), Apurímac, Cuzco y Puno, resulta que los habitantes de estas áreas sumaban 1.740 .819 , mientras que los de la costa eran 863.756 y los de la región oriental $96.189^{64}$. Los primeros, según los datos proporcionados por los subprefectos, elegían a 3.714 electores de segundo grado, los segundos a 1.373 y los terceros a 145 .

Del mismo modo, resulta claro que el mayor número de electores era elegido en zonas rurales. A pesar de que las capitales de las provincias (que eran 95 en aquel momento) eran por lo general los centros urbanos más poblados en su respectiva circunscripción, solo 9 (como se puede leer en la columna F del Cuadro I) tenían la mayoría absoluta de los electores de segundo grado que componían el colegio electoral respectivo, y por supuesto Lima se encontraba entre ellas ${ }^{65}$. Eran 35 las capitales provinciales que llegaban a la mayoría relativa, la cual, sin embargo, a veces correspondía a un número muy reducido de electores, en particular en circunscripciones subdivididas en muchos pequeños distritos.

Sin embargo, las informaciones más interesantes se obtienen comparando los datos relativos al número de electores proporcionados por los subprefectos, con los elaborados por Fuentes a partir de las indicaciones del censo de 1876. Esta comparación lleva a confirmar lo que se ha dicho en las páginas que preceden, acerca de que se había alterado profundamente el proceso de construcción de la representación. Este había sido falseado desde sus mismos cimientos, es decir, la relación entre habitantes y electores de segundo grado. De hecho, aparecen discrepancias sorprendentes: algunos departamentos y provincias elegían un número de electores de segundo grado bastante más elevado de lo que les correspondía atendiendo a su población, mientras que otros, por el contrario, resultaron menos representados de lo que habrían tenido que ser, siempre en relación con el número de habitantes. Aun en el cómputo total se notan diferencias: para Fuentes, la sierra habría tenido que dar 3.469 electores (245 menos de los que elegía en realidad); la costa, 1.713 (340 más); y la región oriental, 195 (50 más). Por supuesto, los electores de la sierra siguen siendo más numerosos que los de la costa, debido a su población, pero las cifras cambian y resulta evidente el hecho de que en la realidad de aquellos años, representada por los datos de los subprefectos, los departamentos de la sierra habían sido favorecidos en la mayoría de los casos.

Llamativo resulta, en particular, el caso de los departamentos de Lima y el Cuzco: el primero, con sus 226.992 habitantes, designaba a 358 electores, cuando en realidad tenía derecho a 423; Cuzco, por el contrario, con sus 238.455 habitantes elegía a 706, cuando en realidad le correspondían 483. Y no es un caso aislado, pues resultados parecidos proporciona la comparación entre, por ejemplo, La Li-

64 Carlos Contreras considera como andinos los departamentos de Áncash y Arequipa. No obstante, en este punto he preferido sustraer del conteo de población y electores las provincias indicadas, que se encuentran en la costa. Carlos Contreras, "Maestros, mistis y campesinos en el Perú rural del siglo XX", en ídem, El aprendizaje del capitalismo. Estudios de historia económica y social del Perú republicano, Lima, Instituto de Estudios Peruanos, 2004, 214-272: 222.

65 Las otras son Arequipa (que en realidad tiene exactamente la mitad de los electores que componen el colegio electoral de la provincia), Cuzco, Calca, Huamanga, Chuquibamba, Ica, Tacna y Moyobamba. En la columna F del Cuadro I, por las razones expresadas en la nota 63, faltan los datos de los departamentos de Apurímac, Huancavelica, Huánuco y Piura. 


\section{CUADRO I}

\begin{tabular}{lrrrrrl}
\hline DEPARTAMENTOS & & & & & & \\
y PROVINCIAS & & & & & & \\
LITORALES o & $\mathbf{A}(1)$ & $\mathbf{B}(2)$ & $\mathbf{C}(3)$ & $\mathbf{D}(4)$ & $\mathbf{E}(\mathbf{5})$ & $\mathbf{F}(\mathbf{6})$ \\
COSTITUCIONALES & $\mathbf{3 4 . 2 4 5}$ & $\mathbf{7 2}$ & $\mathbf{6 9}$ & $\mathbf{7 2}$ & $370(62)$ & \\
\hline & 18.639 & $\mathbf{1 9}$ & $\mathbf{3 8}$ & $\mathbf{2 4}$ & & \\
Amazonas & 266.199 & $\mathbf{4 8 0}$ & $\mathbf{5 3 4}$ & $\mathbf{4 7 6}$ & & \\
Áncash (Costa) & $\mathbf{2 8 4 . 8 3 8}$ & $\mathbf{4 9 9}$ & $\mathbf{5 7 2}$ & $\mathbf{5 0 0}$ & $1.290(131)$ & $7: 4 \mathrm{mr}$ \\
Áncash (Sierra) & $\mathbf{1 1 9 . 2 4 6}$ & $\mathbf{2 8 4}$ & $\mathbf{2 3 8}$ & $\mathbf{2 6 6}$ & $650(96)$ & \\
Áncash (total) & 47.688 & $\mathbf{7 1}$ & $\mathbf{9 7}$ & $\mathbf{7 7}$ & & \\
Apurímac & 109.358 & $\mathbf{2 4 9}$ & $\mathbf{2 2 1}$ & $\mathbf{2 5 1}$ & & \\
Arequipa (Costa) & $\mathbf{1 5 7 . 0 4 6}$ & $\mathbf{3 2 0}$ & $\mathbf{3 1 8}$ & $\mathbf{3 2 8}$ & $527(73)$ & $7: 2 \mathrm{ma}$, \\
Arequipa (Sierra) & $\mathbf{1 4 2 . 2 0 5}$ & $\mathbf{2 2 3}$ & $\mathbf{2 7 6}$ & $\mathbf{3 1 7}$ & $848(132)$ & $6: 1 \mathrm{ma}, 1 \mathrm{mr}$ \\
Arequipa (total) & $\mathbf{2 1 3 . 3 9 1}$ & $\mathbf{3 5 8}$ & $\mathbf{4 2 3}$ & $\mathbf{3 6 0}$ & $1.016(47)$ & $7: 5 \mathrm{mr}$ \\
Ayacucho & $\mathbf{2 3 8 . 4 5 5}$ & $\mathbf{7 0 6}$ & $\mathbf{4 8 3}$ & $\mathbf{7 0 5}$ & $1.349(97)$ & $12: 2 \mathrm{ma}, 4 \mathrm{mr}$ \\
Cajamarca & $\mathbf{1 0 4 . 1 5 5}$ & $\mathbf{1 6 3}$ & $\mathbf{2 0 8}$ & $\mathbf{1 6 9}$ & $723(73)$ & 4 \\
Cuzco & $\mathbf{7 8 . 8 5 6}$ & $\mathbf{1 3 9}$ & $\mathbf{1 5 8}$ & $\mathbf{1 5 2}$ & $570(54)$ & 3 \\
Huancavelica & $\mathbf{6 0 . 1 1 1}$ & $\mathbf{1 0 6}$ & $\mathbf{1 2 1}$ & $\mathbf{1 0 8}$ & $319(14)$ & $2: 1 \mathrm{ma}$ \\
Huánuco & $\mathbf{2 0 9 . 8 7 1}$ & $\mathbf{4 5 6}$ & $\mathbf{4 0 8}$ & $\mathbf{4 5 9}$ & $936(103)$ & $4: 3 \mathrm{mr}$ \\
Ica & $\mathbf{8 5 . 9 8 4}$ & $\mathbf{9 6}$ & $\mathbf{1 7 0}$ & $\mathbf{9 9}$ & $124(16)$ & $2: 2 \mathrm{mr}$ \\
Junín & $\mathbf{1 4 7 . 5 4 1}$ & $\mathbf{2 4 4}$ & $\mathbf{2 9 4}$ & $\mathbf{2 4 4}$ & $572(40)$ & $5: 3 \mathrm{mr}$ \\
Lambayeque & $\mathbf{2 2 6 . 9 9 2}$ & $\mathbf{3 8 8}$ & $\mathbf{4 4 6}$ & $\mathbf{3 8 5}$ & $605(171)$ & $6: 1 \mathrm{ma}, 1 \mathrm{mr}$ \\
Libertad & $\mathbf{6 1 . 1 2 5}$ & $\mathbf{7 3}$ & $\mathbf{1 2 6}$ & $\mathbf{1 0 6}$ & $290(38)$ & $4: 1 \mathrm{ma}, 2 \mathrm{mr}$ \\
Lima & $\mathbf{1 3 5 . 5 0 2}$ & $\mathbf{2 0 2}$ & $\mathbf{2 7 1}$ & $\mathbf{1 9 8}$ & $452(18)$ & 5 \\
Loreto & $\mathbf{2 5 6 . 5 9 4}$ & $\mathbf{5 9 5}$ & $\mathbf{5 2 0}$ & $\mathbf{6 0 0}$ & $1.410(71)$ & $7: 4 \mathrm{mr}$ \\
Piura & $\mathbf{3 6 . 0 1 9}$ & $\mathbf{7 3}$ & $\mathbf{7 2}$ & $\mathbf{2 1}$ & $187(27)$ & $3: 1 \mathrm{ma}, 2 \mathrm{mr}$ \\
Puno & $\mathbf{4 2 . 0 0 2}$ & $\mathbf{3 8}$ & $\mathbf{7 6}$ & & $137(14)$ & 1 \\
Tacna & $\mathbf{2 8 . 7 8 6}$ & $\mathbf{7 1}$ & $\mathbf{5 9}$ & $\mathbf{7 1}$ & $237(7)$ & $1: 1 \mathrm{mr}$ \\
Tarapacá & $\mathbf{3 4 . 4 9 2}$ & $\mathbf{2 0}$ & $\mathbf{6 9}$ & $\mathbf{2 0}$ & $12(1)$ & 1 \\
Prov. Litoral de Moquegua & & & & & & \\
Prov. Constitucional EI Callao & $\mathbf{2 . 6 9 9 . 9 4 5}$ & $\mathbf{5 . 1 3 3}$ & $\mathbf{5 . 3 7 7}$ & $\mathbf{5 . 1 8 0}$ & $12.624(1.285)$ \\
& & & & & & \\
TOTALES & & & & \\
& & & &
\end{tabular}

1. Población según el censo de 1876.

2. $\mathrm{N}^{\circ}$ de electores de segundo grado según los subprefectos.

3. $\mathrm{N}^{\circ}$ de electores de segundo grado según los cálculos de M. A. Fuentes.

4. $\mathrm{N}^{\circ}$ de electores de segundo grado según el Cuadro de 1893.

5 . $\mathrm{N}^{\circ}$ de localidades y pueblos (entre paréntesis) de cada departamento.

6. $\mathrm{N}^{\circ}$ de provincias de cada departamento, con indicación del $\mathrm{N}^{\circ}$ de las provincias cuyas capitales tienen mayoría absoluta (ma) de electores en el Colegio electoral y de las que tienen mayoría relativa (mr). 
bertad y Puno, Lambayeque y Apurímac, Áncash y Junín: Puno tenía 595 electores en lugar de los 520 que le correspondían; Apurímac, 284 en vez de 238; y Junín, 456 en vez de 408. En cambio, La Libertad solo tenía 244, en lugar de 294; Lambayeque, 96 en vez de 170; y Áncash, 499 en lugar de los 572 que le tocaban. Por último, El Callao, con sus 20 electores, resultaba muy perjudicado, pues en realidad tenía derecho a 69.

Estas diferencias pueden ser la consecuencia de la falta de datos censísticos adecuados y puestos al día o, mejor dicho, de la falta de voluntad de emplear los datos disponibles; no obstante, y dada la ausencia de movimientos migratorios importantes, hay que buscar también otras explicaciones. Fuentes había elaborado sus cuadros utilizando el artículo 5 de la ley de elecciones, es decir, dividiendo por 500 el número de habitantes, mientras que había ignorado el artículo 6, el que reconocía a cada pueblo el derecho a tener su propio representante en el colegio electoral provincial. No había sido un error ni un olvido, puesto que Fuentes titulaba cada uno de sus cuadros Cuadro de Electores propietarios y suplentes que deben dar las provincias del Departamento [...] según el censo de 1876, y de conformidad con el artículo 5 de la Ley de Elecciones, y al mismo artículo hacía referencia en la nota que introducía su trabajo. Quizás el intento de Fuentes había sido el de mostrar que, aplicando una relación puramente numérica a los resultados del censo, se podía llegar a rediseñar la geografía política del país, modificando el peso electoral de departamentos y provincias. Profundizando un poco más en el análisis de los casos de Lima y el Cuzco, se puede ver (columna E del Cuadro I) que los 226.992 habitantes del departamento de Lima estaban subdivididos en 605 localidades (ciudades, villas, pueblos, aldeas, caseríos y haciendas), mientras que los 238.445 del Cuzco en 1.394 localidades. Análogas observaciones pueden hacerse en relación con departamentos como La Libertad (572 localidades) y Puno (1.410 localidades), Lambayeque (124 localidades) y Apurímac (650 localidades). Volviendo a la comparación entre Cuzco y Lima, los pueblos legalmente reconocidos no eran tan numerosos en el primer departamento: solo 97, frente a los 171 del segundo ${ }^{66}$. Esto hace suponer que, sobre todo en el área andina -de población mucho más dispersa y mayoritariamente indígena-, núcleos habitados que ya no eran reconocidos como pueblos, o que nunca lo habían sido, habían logrado mantener el derecho-privilegio de designar a su propio elector o apropiarse de él, acabando así por inflar la capacidad de representarse de determinados departamentos y provincias.

Se puede, por lo tanto, concluir que el amplio sufragio, el uso y los abusos del sistema electoral indirecto, incontrolable desde el centro del sistema político, además de la escasa disponibilidad y utilización de recuentos adecuados de la población, habían desplazado hacia la sierra los equilibrios políticos del país. Las conse-

66 Estos datos, como los anteriores, son extraídos del Resumen del Censo General de habitantes del Perú hecho en 1876, Lima, Imprenta del Estado, 1878, 247, 297 y 855. En cuanto a la organización del territorio de los departamentos de Lima y el Cuzco, véase Demarcación política del Perú, op. cit., en particular las páginas 75 y 127. 
cuencias no eran demasiado significativas en lo que se refiere a las elecciones parlamentarias, aunque cuantificaciones maliciosamente equivocadas de la población podían llevar a la elección de un mayor número de diputados por una misma provincia, o a la creación de nuevas provincias, lo que a su vez llevaría a más senadores, pues su número dependía de la cantidad de provincias que cada departamento comprendía ${ }^{67}$. Las consecuencias, en cambio, eran decisivas con respecto al Presidente de la República, que -se puede afirmar- era elegido por los Andes. Y esto era tanto más cierto si se considera el hecho de que, como demuestran ulteriores datos contenidos en el opúsculo de Fuentes, los electores de segundo grado de las provincias andinas eran mucho más solícitos que los colegas costeños al expresar su sufragio: en las elecciones presidenciales de 1872 había votado el $77 \%$ de los electores de la costa y el 80\% de los andinos, mientras que en 1876 los porcentajes fueron el $59 \%$ y el $73 \%$, respectivamente ${ }^{68}$.

\section{LA REFORMA DE 1895: UNA GEOGRAFÍA POLÍTICA DIFERENTE, UN NUEVO CIUDADANO, UNA NUEVA ÉLITE}

El cambio vino por fin con las reformas de 1895 y 1896 . De sufragio -como se dijo anteriormente- se había discutido en muchas oportunidades, sobre todo entre 1874 y 1878 , cuando se debatió un proyecto presentado en 1873, que, entre muchas otras innovaciones, proponía hacer más rígidos y sobre todo cuantificables los requisitos exigidos para el electorado activo de primer grado, lo que comportaría una significativa reducción del cuerpo electoral ${ }^{69}$. De hecho, en su artículo 40 el proyecto establecía que no podía ser considerado capaz de escribir el que solo sabía firmar; que "jefes de taller" eran únicamente quienes "tienen establecimiento público y pagan la patente que les corresponde"; y que propietarios debían ser considerados, en relación con el derecho de sufragio, los que "poseen un fundo que rente más de cien soles al año"70. Sin embargo, el proyecto no prosperó.

67 Según la Constitución de 1860 (art. 46), se elegía “un Diputado propietario y un suplente cada treinta mil habitantes, ó por cada fracción que pase de quince mil, y por cada provincia, aunque su población no llegue á este número". Con respecto a los senadores (art. 48), se elegían cuatro en los departamentos que tenían más de ocho provincias, tres en los que tenían menos de ocho y más de cuatro, dos en los que tenían menos de cinco y más de una, y uno en los departamentos que tenían una sola provincia y en cada provincia litoral.

68 Ministerio de Gobierno. Dirección de Estadística, Estadística electoral y parlamentaria del Perú, op. cit., 31 y 32.

69 Véase nota 16.

70 El proyecto formaba parte del programa de gobierno de Manuel Pardo, el cual, en su campaña electoral, se había dirigido al ciudadano "virtuoso", "justo e independiente", "a todos los hombres laboriosos que constituyen la nación" [véase Carmen McEvoy, La Utopía republicana. Ideales y realidades en la formación de la cultura política peruana (1871-1919), Lima, Pontificia Universidad Católica del Perú, 1997, 50-70]. Sobre el apoyo que le brindaron los artesanos de Lima, que se autodefinían como "el mayor número de ciudadanos de que se compone la asociación política de la Nación", véase Iñigo García Bryce Weinstein, República con ciudadanos: los artesanos de Lima, 1821-1879, Lima, Instituto de Estudios Peruanos, 2008, 208. 
La discusión se reanudó en 1887 y con mayor determinación en 1890, cuando se puso en marcha el largo y laborioso proceso de reforma del artículo 38 de la Constitución. Ese año, la reforma fue aprobada por ambas Cámaras, pero, al ser de índole constitucional, tenía que ser sancionada por otra legislatura. En 1891, siendo diferente la composición de la Cámara de Diputados (que se renovaba por tercios cada dos años), el acuerdo se frustró, de modo que para la aprobación definitiva se tuvo que esperar hasta 1895, cuando la restricción del sufragio únicamente a los alfabetizados se convirtió en realidad. En el año siguiente fue aprobada también la nueva ley electoral, que rediseñaba todo el proceso de construcción de la representación, introduciendo el sufragio directo y público, en doble cédula firmada, y modificando toda la marcha del proceso mismo. Según la ley de 1861, la convocatoria a elecciones por parte del Ejecutivo daba lugar a una serie de procesos autónomos, que se desarrollaban en el ámbito parroquial y provincial, y solo al final regresaban a Lima para la calificación de los elegidos por parte de las Cámaras. Con la nueva ley, en cambio, resultaba decisivo el papel de un organismo central con sede en la capital, la Junta Electoral Nacional, compuesta por representantes de los tres poderes, la que podía ejercer directa o indirectamente cierto control sobre la composición de los múltiples organismos (en los cuales los mayores contribuyentes de cada localidad tenían un lugar importante), que en departamentos, provincias y distritos se encargaban de las distintas fases del proceso, desde la redacción del registro cívico hasta el escrutinio de los votos emitidos.

¿Por qué fue posible en ese momento cortar los nudos del sufragio, llevando a cabo unas reformas sobre las cuales mucho se había discutido inútilmente en los años precedentes? Indudablemente, desde la mitad del siglo el país había empezado a cambiar, gracias al guano y a las múltiples consecuencias que los ingresos proporcionados por el abono habían producido en la economía y la sociedad. En el ámbito político, los cambios habían empezado a notarse durante la presidencia de Manuel Pardo, jefe del Partido Civil, pero se trataba de procesos largos y contradictorios, que las dificultades financieras y la guerra, con su secuela de conflictos internos y de verdadera pulverización del poder central, se habían encargado de bloquear. En 1895, la elección como Presidente de Nicolás de Piérola, después de la violenta expulsión del poder del general Andrés Avelino Cáceres y el fin del llamado 'segundo militarismo', marcó el comienzo de una nueva fase, en la cual - para emplear las palabras del mismo Piérola- se había vuelto objetivo prioritario la consecución de la "paz pública [...], sin la cual no habrá ley ni autoridad respetable ni respetada, no quedará posibilidad siquiera de bien para la República"71. Piérola había llegado al poder con el apoyo de una coalición inédita, formada por el Partido Demócrata, que él mismo había fundado en 1884, y por el Partido Civil, su adversario histórico y hasta poco tiempo antes aliado de Cáceres ${ }^{72}$. En el Partido

71 Véase Pedro Ugarteche Tizón y Evaristo San Cristóbal (compiladores), Mensajes de los presidentes del Perú, Lima, 1945, citado en Basadre, Elecciones y Centralismo, op . cit., 50.

72 Un análisis del gobierno de Cáceres y del proceso que llevó al poder a la Coalición Nacional, liderada por Piérola, puede encontrarse en McEvoy, La Utopía republicana, op. cit., en particular los capítulos 5 y 6 . 
Civil encontraba ahora su expresión buena parte de aquella nueva élite económica, surgida de la catástrofe de la guerra, ligada directa o indirectamente a la producción de materias primas para la exportación (minerales, lanas, azúcar, arroz, algodón, etc.), pero activa también en el sector manufacturero y los servicios, la cual quería poner en marcha un proceso de transformaciones rápidas ${ }^{73}$. Tras la aprobación en 1889 del contrato Grace, que había cerrado el contencioso sobre la deuda externa y reactivado el comercio y los canales del crédito internacional, en el país se habían desarrollado procesos importantes: concentración de la propiedad de la tierra y mecanización de la producción, sobre todo en la costa norte; ampliación de líneas ferroviarias, particularmente en el sur; aparición de un número creciente de sociedades por acciones en la banca, en el sector de los seguros, en la agricultura, la minería y la industria; fundación de cámaras de comercio; creación de fuertes asociaciones empresariales, como la Sociedad Nacional de Agricultura, la de Minería y la de Industrias ${ }^{74}$.

En esta fase de modernización, en que se abrían posibilidades de crecimiento económico, el presupuesto necesario era el orden, que no se conseguiría sin el apoyo de una base social y de unas élites políticas y de gobierno que compartieran las mismas ideas, el mismo proyecto modernizador. Por eso, los gobernantes de la época consideraron como una imprescindible necesidad la de rediseñar todo el escenario político, reduciendo sus dimensiones y modificando radicalmente sus características, reforzando el peso del Perú blanco y mestizo, costeño y urbano, en lugar del rural y andino, con el objetivo de adaptar la base social a su proyecto de país y de nación.

En esta dirección se movían las reformas de 1895 y 1896, la primera en particular, cuya consecuencia más evidente -como se dijo en las primeras páginas- fue la reducción del cuerpo electoral. No es fácil hacer una comparación entre la situación anterior y la que se dio después de 1896, porque no ha sido posible encontrar datos relativos al número de sufragantes de primer grado en el período de vigencia del sufragio indirecto; solo sabemos que hacia 1891, según lo afirmó un diputado, eran más o menos 400.000 los peruanos que "han poseído y poseen el derecho de sufragio"75. Sin embargo, en las elecciones de 1860, según los datos oficiales comunicados al Congreso, habían sufragado 707.955 ciudadanos, la casi totalidad de los varones mayores de 20 años, que de acuerdo con el censo de 1876 eran 782.014. No obstante, hay que anotar que en ese período estaba en vigencia la Constitución de 1856, que preveía un sufragio casi universal y directo, y que las cifras eran muy probablemente exageradas ${ }^{76}$.

73 Sobre las características de esta élite, véase Alfonso W. Quiroz, Domestic and Foreign Finances in Modern Peru (1850-1950): Financing Visions of Development, Pittsburgh, University of Pittsburgh Press, 1993.

74 Véase la primera parte de Manuel Burga y Alberto Flores Galindo, Apogeo y crisis de la República Aristocrática. Oligarquía, aprismo y comunismo en el Perú (1895-1932), Lima, Ediciones Rikchay Perú $\mathrm{N}^{\circ} 8,1979,11-86$.

75 Congreso Ordinario de 1891, Diario de los Debates de la Cámara de Diputados, s.p.i, 629.

76 Los datos fueron dados a conocer el 31 de julio de 1860 , en el curso de la tercera sesión del Congreso. Véase Diario de los Debates. 1860. Congreso, sin portada, s.p.i, 13. 
Datos relativos a unos años en que se realizaron elecciones presidenciales después de la reforma de 1895 han sido sintetizados en el Cuadro II. En la primera columna se encuentra el número de electores de segundo grado de $1893 \mathrm{y}$, en las siguientes, los datos (desagregados por departamentos) referidos a los ciudadanos inscritos en los registros electorales (cuando ha sido posible establecer su número) y a los sufragantes en los años 1899, 1908, 1915 y 1931, cuando por fin se conoció de forma fiable la composición electoral del país ${ }^{77}$. A pesar de las muchas reformas que se aprobaron desde 1895-1896, nada cambió hasta 1931 con respecto a los requisitos para el ejercicio del sufragio: la innovación más significativa fue la introducción en este último año del sufragio secreto.

Respecto del Cuadro II, para una mejor comprensión del mismo, hay que señalar que, en los casos de los departamentos de Áncash y Arequipa, los datos disponibles han sido divididos en dos partes, relativa la primera a las provincias situadas en la costa y la segunda a las de la sierra, con el objeto de reproducir la distinción hecha anteriormente a propósito de los electores de segundo grado. Al lado de las columnas de datos se ha colocado el porcentaje de cada departamento, calculado en relación con el total nacional de inscritos o sufragantes de cada año. Prácticamente, en todos los años a los que se hace referencia falta información de alguna provincia o departamento: a veces se trata de circunscripciones recientemente establecidas, otras veces de datos que no se encuentran en las fuentes consultadas por razones diferentes (por ejemplo, por la anulación de las elecciones). A los datos contenidos en el Cuadro II podemos finalmente agregar los que proporciona Basadre, según los cuales en 1904 los inscritos en todo el país fueron 146.990 y los sufragantes $97.719^{78}$.

La disminución del número de los ciudadanos con derecho de sufragio resulta impresionante en 1899, cuando los inscritos en los registros fueron 108.597 y solo la mitad se acercó a las mesas electorales ${ }^{79}$. En los años siguientes, las cifras relativas a inscritos y sufragantes subieron progresivamente, pero siempre se mantuvieron muy por debajo de lo que habían sido antes de la reforma; se debe tener en cuenta que, mientras tanto, había crecido también la población, como se puede notar en el Cuadro III, en el cual, al lado de los datos demográficos de 1876, se han puesto los extraídos del censo de 1940. Asimismo, el resultado más significativo (y

77 El dato relativo a los sufragantes de 1899 se encuentra en el "Cuadro $\mathrm{N}^{\circ} 1$ ", en Congreso Ordinario de 1899, Diario de los Debates de Congreso, Lima, Imprenta de El Comercio, 1899, 34 y 35. Respecto de 1908, véase "Cuadro número 1. Cómputo general de los sufragios emitidos en la República en las elecciones practicadas durante los días 25, 26, 27 y 28 de mayo de 1908 para Presidente de la República", en Legislatura Ordinaria de 1908, Diario de los Debates de las Sesiones de Congreso, Lima, Imprenta de El Comercio, 1908, 50. Para el año de 1915, véase "Cuadro número 1. Resultado de la elección para Presidente de la República en 1915”, en Legislatura Ordinaria y Extraordinaria de 1915, Diario de los Debates de las Sesiones de Congreso, Lima, Tipografía de La Prensa, 1916, 41-45. Los datos de 1931 se encuentran en República del Perú. Dirección Nacional de Estadística. Servicio de Estadística Electoral, Extracto estadístico y Censo electoral de la República, Lima, Taller de Linotipia, 1933, 230.

78 Basadre, Elecciones y Centralismo, op. cit., 66.

79 El dato nacional (no desagregado por departamentos) se encuentra en Basadre, Historia de la República del Perú, op. cit., XI:18. 


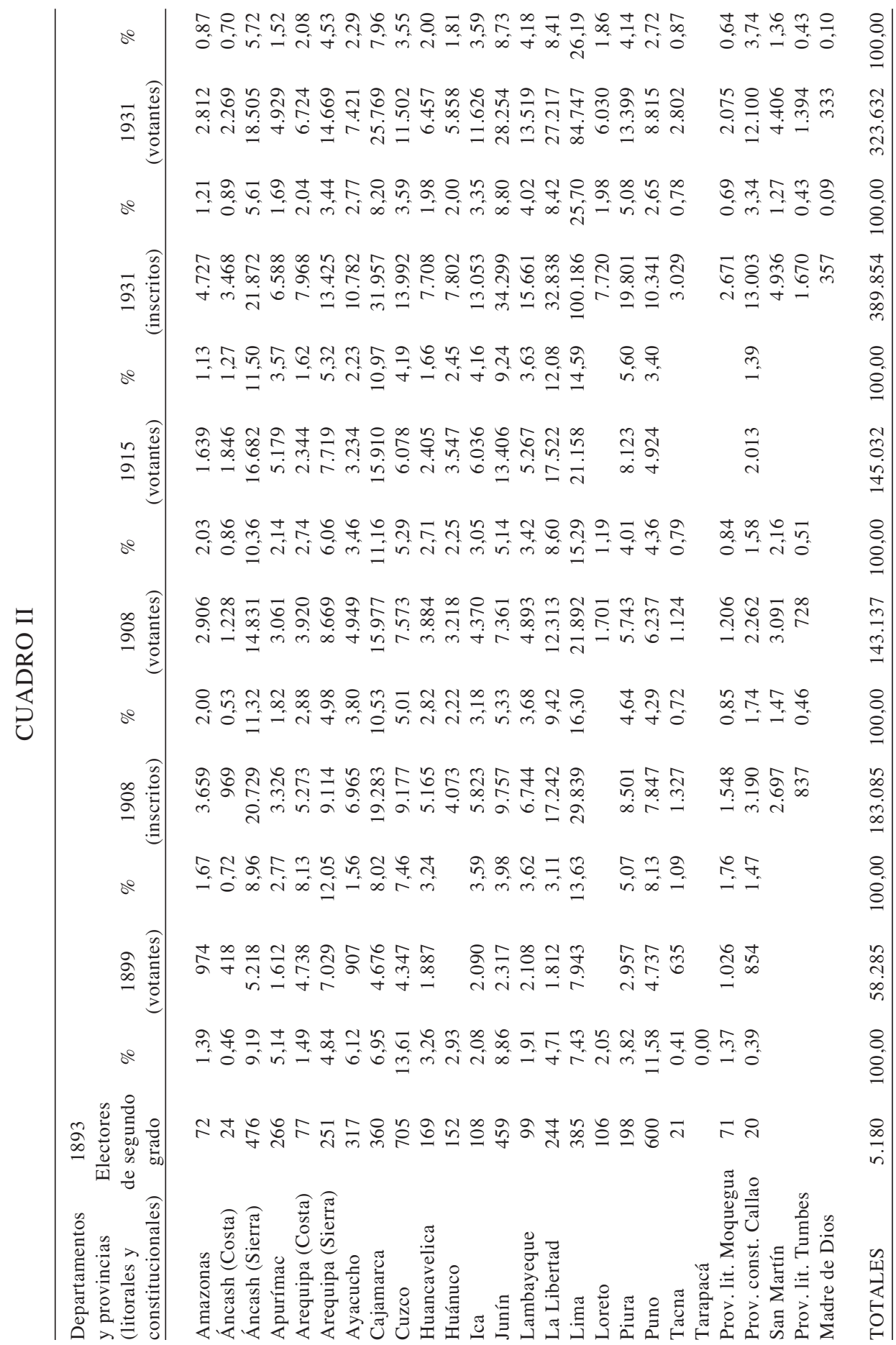


esperado) de la reforma fue el cambio profundo que se produjo en la geografía electoral, desplazando progresivamente hacia la región costeña el centro de gravedad política del país.

Según los datos disponibles, en 1893 los departamentos de la costa designaban el 24,07\% de los electores de segundo grado; los de la sierra, el 72,49\%; y los de la selva el $2,82 \%$. En 1899, los sufragantes residentes en la costa constituían el $42,17 \%$ del total; los de la sierra, el 56,15\%; y los de la selva, el 1,67\%. El saldo se volvió cada vez más favorable a la costa en los años siguientes: los porcentajes de los votantes de esta región y los de la sierra fueron, respectivamente, el 41,69\% y el $52,94 \%$ en 1908 , el $44,34 \%$ y el $54,53 \%$ en 1915 , hasta que finalmente, en 1931 , la costa dio el $54,96 \%$ de los sufragantes, logrando sobrepasar a la sierra, que solo llegó al 40,84\% $\%^{80}$. En ese año, la población electoral (inscrita) del país se componía de un 59,78\% de mestizos, 24,96\% de indígenas, $14,31 \%$ de blancos y $0,95 \%$ de negros ${ }^{81}$. Por supuesto, a lo largo del período se había producido también un importante crecimiento demográfico, pero, si se observa el Cuadro III, se puede notar que todavía no se habían dado cambios radicales en la distribución de la población: si en 1876 el 29,53\% de la población residía en los departamentos de la costa y el $66,74 \%$ en los de la sierra, los porcentajes correspondientes en 1940 eran el $31,51 \%$ y el $60,55 \% 82$.

Retomando lo que se dijo páginas atrás acerca del peso político de los departamentos de Lima y el Cuzco, resulta particularmente significativo el cambio que se dio a partir de 1899. En 1893, los electores de segundo grado designados por el departamento de la capital constituían el 7,43\% del total y los del Cuzco el 13,61\%; mientras que en 1899, los sufragantes de Lima representaban el 13,63\% y los del Cuzco el 7,46\%. Este porcentaje siguió bajando, hasta llegar en 1931 al $3,55 \%$, mientras que el de Lima subió al 26,19\%.

En términos generales, los más afectados por la reforma fueron los departamentos del sur andino, donde se concentraba una gran parte de la población indígena. Así, el peso electoral de Puno (92,18\% de indígenas según el censo de 1876) bajó del 11,58\% de electores de segundo grado de 1893 al 2,72\% de sufragantes de 1931. Situaciones similares ocurrieron en Huancavelica $(78,51 \%$ de indios), que pasó de 3,26\% en 1893 a 2,00\% en 1931; Ayacucho (72,30\% de indios), que en el mismo período bajó de 6,12\% a 2,29\%; y Apurímac $(54,57 \%$ de indios), de 5,14 a $1,52 \% 83$.

Por supuesto, la fuerte reducción del cuerpo electoral representaba uno de los objetivos que los legisladores de 1895 se habían propuesto. Isaac Alzamora, al presentar la propuesta elaborada por la comisión parlamentaria que él mismo presidía, afirmó rotundamente que el gran número de los que quedarían excluidos del

80 Con respecto a la zona oriental del país (la selva), los sufragantes fueron el 5,37\% del total en 1908 , el $1,13 \%$ en 1915 y el $4,19 \%$ en 1931 .

81 República del Perú. Dirección Nacional de Estadística. Servicio de Estadística Electoral, Extracto estadístico y Censo electoral, op. cit., 218.

82 La selva pasó del 3,51\% en 1876 al 7,93\% en 1940.

83 Junín, en cambio, logró mantener una presencia casi idéntica: sus electores (de segundo grado) constituyeron el $8,86 \%$ en 1893 y el $8,73 \%$ en 1931 . 
sufragio no podía ser un argumento en contra de la implementación de la reforma, dado que "precisamente este hecho, que revela la magnitud del mal, exije la urgencia del remedio", pues, concluyó, "no está en el interés de la nación que elijan muchos, sino el que se elija bien" 84 . El cambio esperado no tenía que ser únicamente cuantitativo, sino cualitativo y, de hecho, la selección del criterio de alfabetización como requisito único para el ejercicio del derecho de sufragio implicó la redefinición del ciudadano-elector. El nuevo ciudadano residía principalmente en las áreas urbanas y en la costa, era culturalmente blanco y consciente de sus responsabilidades, en cuanto él mismo tenía que pedir la inscripción en el registro cívico, y expresaba públicamente su voto ${ }^{85}$. Anteriormente, el derecho de sufragio amplio e indirecto de matriz gaditana y los requisitos vagos, definidos en el ámbito de las comunidades locales, habían permitido la supervivencia de una ciudadanía 'municipal', de lealtades y de pertenencias de molde localista. La reforma, en cambio, proponía (o mejor dicho, imponía) una ciudadanía 'nacionalizada', basada en una monoidentidad definida por la posesión de la cultura escrita. La compilación de los registros electorales seguiría siendo un momento de conflicto: en el Perú, como en cualquier país, la redacción de la lista de ciudadanos hábiles para sufragar no constituía el registro burocrático de una realidad objetiva, sino el instrumento para la construcción de un cuerpo electoral que podía cambiar según los equilibrios políticos del momento. Pero este conflicto se desarrollaba en un espacio político más reducido, del cual había sido definitivamente excluida una parte importante del universo rural, en particular el mundo de los pueblos y las comunidades indígenas de los Andes.

Las consecuencias fueron inmediatamente visibles con respecto a la elección del Presidente de la República, que por fin logró liberarse de la 'hipoteca andina', del peso decisivo de 'grandes electores', como los 706 del departamento del Cuzco, que anteriormente habían tenido que ser absolutamente estratégicos para construir alianzas que tuvieran posibilidades de victoria. En los años sucesivos, los presidentes elegidos (Eduardo López de Romaña, Manuel Candamo, José Pardo y Barreda, Augusto B. Leguía y Guillermo Billinghurst) fueron hombres de la costa, directamente implicados o fuertemente relacionados con importantes negocios de exportación.

Se debe agregar finalmente que las consecuencias fueron menos significativas -por lo menos desde un punto de vista cuantitativo- en lo que se refiere a diputados y senadores, pues la ley de 1896 mantuvo la elección por provincias y departamentos y la relación entre población y representantes. Hasta se puede decir que la situación empeoró y se volvieron más evidentes los límites de la

84 Congreso Ordinario de 1895, op. cit., 443.

85 La ley electoral de 1896 establecía que en el registro electoral tenían que inscribirse los nombres de los que "lo solicitaren, con expresión del lugar de su nacimiento, domicilio, estado, profesión ó ejercicio, y la calidad de saber leer y escribir" (art. 27). Prescribía además que "todo voto se emitirá en dos cédulas perfectamente iguales, que llevarán el número de la boleta de inscripción del sufragante" (art. 57), y que "una de las cédulas firmadas por el Presidente de la comisión receptora, será inmediatamente devuelta al votante; y la otra, firmada por este, quedará en poder de la Comisión, como comprobante del sufragio" (art. 59). 
representación por provincias, porque -de hecho- los diputados de departamentos andinos, que tenían un número más reducido de votantes, necesitaron para ser elegidos de una menor cantitad de sufragios $^{86}$. No obstante, si se analizan las listas de los miembros de ambas Cámaras y de los Congresos constituyentes en los años comprendidos entre 1860 y 1918 , se puede apreciar que se verificó lo que definiría como una 'cristalización' y 'verticalización' de la representación. Daré unos ejemplos a continuación.

\section{CUADRO III}

\begin{tabular}{|c|c|c|c|c|}
\hline \multirow{2}{*}{$\begin{array}{l}\text { DEPARTAMENTOS y PROVINCIAS } \\
\text { (litorales y constitucionales) }\end{array}$} & \multirow{2}{*}{$\begin{array}{l}\text { Población } \\
1876\end{array}$} & \multicolumn{3}{|c|}{ Población } \\
\hline & & $\%$ & 1940 & $\%$ \\
\hline Amazonas & 34.245 & 1,27 & 89.560 & 1,28 \\
\hline Áncash & 284.091 & 10,52 & 465.135 & 6,62 \\
\hline Apurímac & 119.246 & 4,42 & 280.213 & 3,99 \\
\hline Arequipa & 160.282 & 5,94 & 270.996 & 3,86 \\
\hline Ayacucho & 142.205 & 5,27 & 414.208 & 5,90 \\
\hline Cajamarca & 213.391 & 7,90 & 568.118 & 8,09 \\
\hline Cuzco & 238.455 & 8,83 & 565.458 & 8,05 \\
\hline Huancavelica & 104.155 & 3,86 & 265.557 & 3,78 \\
\hline Huánuco & 78.856 & 2,92 & 276.833 & 3,94 \\
\hline Ica & 60.111 & 2,23 & 144.547 & 2,06 \\
\hline Junín & 209.871 & 7,77 & 500.161 & 7,12 \\
\hline Lambayeque & 85.984 & 3,18 & 199.660 & 2,84 \\
\hline La Libertad & 147.541 & 5,46 & 404.024 & 5,75 \\
\hline Lima & 226.992 & 8,41 & 849.171 & 12,09 \\
\hline Loreto & 61.125 & 2,26 & 321.341 & 4,58 \\
\hline Piura & 135.502 & 5,02 & 431.487 & 6,14 \\
\hline Puno & 256.594 & 9,50 & 646.385 & 9,20 \\
\hline Tacna & 36.019 & 1,33 & 37.512 & 0,53 \\
\hline Tarapacá & 42.002 & 1,56 & 0 & 0,00 \\
\hline Prov. lit. Moquegua & 28.786 & 1,07 & 35.709 & 0,51 \\
\hline Prov. const. Callao & 34.492 & 1,28 & 84.438 & 1,20 \\
\hline San Martín & & & 120.913 & 1,72 \\
\hline Prov. lit. Tumbes & & & 26.473 & 0,38 \\
\hline Madre de Dios & & & 25.212 & 0,36 \\
\hline TOTALES & 2.699 .945 & 100,00 & 7.023 .111 & 100,00 \\
\hline
\end{tabular}

86 Según los cálculos de Basadre, si en teoría cada representante elegido al Congreso constituyente de 1931 había recibido en promedio alrededor de 3.000 votos, en realidad un representante del Cuzco solo había recibido 992, mientras que uno de Lima, para ser elegido, había tenido que obtener 6.679. Véase Basadre, Elecciones y Centralismo, op. cit., 155-158. 
La provincia de Lima eligió como diputados, entre 1860 y 1898, a 48 personas, mientras que en los años siguientes -de 1899 a 1918- los elegidos fueron 9, cuatro de los cuales se mantuvieron en el cargo por seis años y uno por ocho. En Arequipa, los elegidos fueron 19 en el primer período y 8 en el segundo; en Trujillo, 4 y 3 (uno, Luis José de Orbegoso, permaneció en su escaño de 1907 a 1918); en el Cuzco, 8 y 3; y en Puno, 12 y 7. Algo muy parecido pasó con los senadores: el departamento de Lima eligió a 20 representantes en el primer período y a 11 en el segundo, cinco de los cuales ocuparon el cargo por seis años, y uno, Ántero Aspíllaga, por dieciséis. En Arequipa, los elegidos como senadores fueron 23 entre 1860 y 1898 y 10 entre 1899 y 1918; en La Libertad, 24 y 5 (entre los cuales Víctor Larco Herrera, José Ignacio Chopitea y Agustín G. Ganoza eran hacendados azucareros); en el Cuzco, 27 y 9; y en Puno, 22 y $7^{77}$. Por supuesto, las razones que concurrieron a crear esta situación fueron muchas: entre otras, la mayor estabilidad política del segundo período considerado y ciertos aspectos de la ley electoral de 1896, que -como se dijo anteriormente- había elaborado un proceso de construcción de la representación más centralizado, en el cual, para ganar, era necesario contar con relaciones importantes en la capital $^{88}$. Así se consiguió que llegaran a Lima personajes en su mayoría confiables, en plena sintonía con las expectativas de la élite de gobierno.

\section{¿Y LOS INDIOS? DE LA ‘NACIÓN CÍVICA' A LA “NACIÓN CIVILIZADA'89}

Por muchas y profundas que fueran las consecuencias de la reforma de 1895, la introducción del requisito de alfabetización no sorprende, pues se trata en realidad de uno de los criterios más difundidos y utilizados en buena parte del siglo en muchos países americanos y, sobre todo, europeos. Puede más bien sorprender el hecho de que sea el único y que se haya introducido tan tarde. En el debate que precedió a la aprobación de la reforma de 1895 se esbozó la posibilidad de introducir también la obligación de pagar alguna contribución al Estado, para evitar así que pudieran sufragar los "tinterillos", es decir, esos individuos, muy numerosos en las capitales de provincia, que aun sabiendo leer y escribir "son unos verdaderos vagos $[\ldots]$ y se entregan á todo género de abusos en los períodos electorales" ${ }^{90}$. No

87 Véase Víctor E. Ayarza, Reseña histórica del Senado del Perú. 1821-1921, Lima, Imprenta Torres Aguirre, 1921, e Ismael Echegaray Correa, La Cámara de Diputados y las Constituyentes del Perú, 1822-1965, Lima, Imprenta del Ministerio de Hacienda, 1965.

88 Sobre las sucesivas leyes electorales y los resultados de su implementación, véanse Gabriella Chiaramonti, "Riforma elettorale e centralismo notabilare a Trujillo (Perú) tra Otto e Novecento", en Quaderni Storici N.S. 69: Notabili, elettori, elezioni Rappresentanza e controllo elettorale nell'800, Bologna, 1998, 903-927, y Víctor Peralta Ruiz, "Los vicios del voto: el proceso electoral en el Perú, 1895-1929”, en Aljovín de Losada y López (ed.), Historia de las elecciones en el Perú, op. cit., 75-107.

89 Tomo prestados los dos conceptos del artículo de Mónica Quijada, “¿Qué nación? Dinámicas y dicotomías de la nación en el imaginario hispanoamericano del siglo XIX”, en François-Xavier Guerra y Mónica Quijada (coords.), Cuadernos de Historia Latinoamericana 2: Imaginar la nación, Münster, Hamburg, 1994, 15-51.

90 Congreso Ordinario de 1890, Diario de los Debates de la H. Cámara de Senadores, Lima, Imprenta de El Comercio, s.f., 651. 
obstante, la propuesta no tuvo acogida. Se dijo que la contribución personal había suscitado muchas quejas, al punto de que no se podía cobrar sino por la fuerza, y que el mismo gobierno estaba en contra de ella. Si se ponía como condición para el sufragio el pago de otras contribuciones directas, se quedaría la mayor parte de la república privada del derecho de sufragio, porque en la mayoría de los pueblos no se pagaba ni la contribución industrial de patentes ni la predial, debido al hecho de que "las industrias son insignificantes, y el valor de la propiedad, que está muy dividida, resulta demasiado reducido" 91 .

Con respecto al sufragio de los analfabetos, muchas veces se había discutido sobre el tema, con argumentos que habían ido cambiando de manera sustantiva a lo largo del siglo. El primer debate importante, y quizás el más conocido, es el que se desarrolló en 1849, cuando se discutía un decreto que contemplaba una nueva prórroga hasta 1860 del plazo en que indígenas y mestizos analfabetos podían votar. En aquella oportunidad, Bartolomé Herrera, sacerdote ultramontano, líder del Partido Conservador y defensor de la 'soberanía de la inteligencia', sostuvo que los analfabetos -fueran ellos indígenas, mestizos, blancos o negros- no tenían, por su ignorancia, la capacidad de ejercer con conciencia el derecho de sufragio y, por lo tanto, no debían sufragar. El prelado terminó su intervención afirmando que él también quería a los indios y que justamente por esta razón estaba convencido de que lo mejor que se podía hacer para mejorar su condición era invertir "una buena porción de la renta pública en escuelas", que debían fomentar su educación e instrucción ${ }^{92}$. En la respuesta de los liberales, y en particular en las palabras de Pedro Gálvez, su más prestigioso representante, se percibe el eco de las recientes revoluciones europeas y, especialmente, de los acontecimientos en Francia. Sería monstruoso -dijo Gálvez- que, cuando "un movimiento de renovación jeneral anima á todo el mundo y parece presidir á la civilización del siglo XIX”, las leyes peruanas mantuvieran normas que degradaban a quienes las imponían y a quienes tenían que obedecerlas. Privar del sufragio a los indígenas, hombres libres y racionales, solo porque eran analfabetos, significaba endosarles a ellos las responsabilidades de los gobiernos republicanos que no habían sabido o querido promover su desarrollo físico e intelectual, y hacerles todavía pagar el precio de los tres siglos de despotismo a que los había sometido la tiranía española. Para votar no era necesario saber leer y escribir, porque ello significaría plantear una condición ficticia y, por lo tanto, tiránica y opresiva: para formar parte de una sociedad política no se podían exigir otros requisitos que los existentes en la naturaleza misma. Al concluir, volvía en el discurso de Gálvez la referencia a la situación francesa: en la cuna de la revolución, la mayoría de la población sabía leer y escribir y, por lo tanto, la exclusión del sufragio de los analfabetos no era una

91 Ibid., 658 .

92 Extracto de las Sesiones de la Cámara de Diputados. El opúsculo, conservado en la Biblioteca Nacional del Perú, no tiene pie de imprenta y las páginas carecen de numeración. Los argumentos a los que hago referencia en el texto se encuentran en particular en las páginas 7 y 8 y desde la 14 hasta la 25. Acerca del pensamiento de Bartolomé Herrera, el estudio más reciente es el de Víctor Samuel Rivera, "Tras el incienso. El republicanismo reaccionario de Bartolomé Herrera", en Araucaria. Revista Iberoamericana de Filosofía, Política y Humanidades 20, Sevilla, 2008. 
medida demasiado opresiva; sin embargo, de todas formas allí se había decidido abrir "con franqueza las puertas de la nación á todo hombre que quiere ser miembro suyo". Esta afirmación me parece el punto central de los argumentos de los liberales, que se repetía, aunque en formas distintas, en todos sus discursos: lo que querían era hacer del sufragio el vínculo mediante el cual se pudiera construir y consolidar el edificio de la nación. El diputado Gamboa sostuvo que a nadie podía negarse el derecho de concurrir a la formación del gran pacto social, y mucho menos a los que constituían la gran mayoría de una nación; hacerlo significaría que en realidad los indígenas y mestizos eran considerados como esclavos, como bestias de carga que "vejeta[ban] encorbados rumiando el pasto", unidos al Perú por vínculos de dolor y sufrimiento, en concreto para ser explotados y ofrendar su sangre inocente en los campos de batalla. Y Gómez Farfán concluyó que, para el hombre salido del estado natural y constituido en sociedad, no había privación comparable a la de la ciudadanía, porque "el derecho de ser ciudadano en ejercicio y el derecho de sufragio forman [...] su existencia social"93.

En las palabras de Gálvez y de sus correligionarios, junto al eco del 48 francés, se reconoce también la referencia a los tres siglos de despotismo y opresión, que había sido uno de los argumentos retóricos más repetidos por los diputados americanos en las aulas de Cádiz y por los líderes independentistas. Y en realidad, hay un elemento más que unía a los liberales de 1849 con los hombres de la generación de la Independencia, y es la voluntad de hacer de la nación un proyecto incluyente, a pesar de las muchas diferencias y de los fuertes contrastes que existían en su interior. Como lo afirma Quijada, estaban convencidos de que "la dimensión institucional de la nación se sobrepondría a la cultural, neutralizando la fuerza centrípeta de la diversidad mediante la cohesión fundada en la identidad global de la "ciudadanía" "94. En un país como el Perú de mediados del siglo XIX, en el cual los derechos civiles proclamados en las constituciones no podían ser aplicados por ausencia de las instituciones que habrían debido implantarlos concretamente ${ }^{95}$, la ciudadanía no podía ser sino esencialmente política, y el sufragio tenía que ser el vínculo que uniera a los ciudadanos entre sí y, al mismo, tiempo un derecho constructivo, una escuela de civismo, cuyo ejercicio dejaría emerger progresivamente la comunidad de los ciudadanos-electores, la 'nación cívica'.

En su intervención, Herrera culpó a los liberales de una suerte de racismo al revés, porque el texto del decreto que se debatía hacía referencia a indígenas y mestizos, sin contemplar la posibilidad de que existieran blancos pobres, negros y mulatos que no supieran leer y escribir. Esta identificación se acentuó todavía más en los años siguientes, cuando al hablar de analfabetos resulta claro que los oradores se referían casi exclusivamente a los indígenas. Así pasó, por ejemplo, en 1874

93 Extracto, op. cit., 15.

94 Quijada, ¿Qué nación?”, op. cit., 43.

95 Hace notar Norberto Bobbio que el punto de vista según el cual los derechos civiles, en la tradición anglosajona, representaban el concepto negativo de la libertad, es decir, la idea de la no interferencia del Estado en la vida privada de los ciudadanos, soslaya el hecho de que ese mismo concepto exija la acción del Estado y la creación de instituciones estatales para su defensa. Norberto Bobbio, L'età dei diritti, Torino, Einaudi, 1997, 72. 
y 1878, cuando se debatió el proyecto de ley de censo, registro cívico y elecciones, que -como se indicó antes- no llegó a ser aprobado. Los parlamentarios favorables a privar del voto a los analfabetos y a introducir eventualmente el sufragio directo afirmaron rotundamente que no había que continuar engañando al pueblo con "farsas democráticas": si el indio no tenía aptitud cívica para votar con conciencia ni energía suficiente para resistir las coacciones, "que no sufrague, ni directa ni indirectamente" 96 . A argumentos como este, los que estaban en contra de las reformas propuestas contestaron que les preocupaba la fuerte reducción del cuerpo electoral que tales medidas implicarían, hasta el punto de desvirtuar por completo "nuestro sistema esencialmente democrático" y llegar a una situación en la que "votaría un 90 por ciento menos de los individuos que forman la nación”. En consecuencia -concluyó un diputado-, se tendría un "derecho de soberanía que no es de la nación, sino de la minoría; lo cual es un absurdo". Una vez más, el problema estaba en el atraso y la falta de educación de los indígenas, cuya responsabilidad, sin embargo, ya no se hacía recaer en la opresión del régimen colonial, sino en los gobiernos "que desde la Independencia no han hecho lo posible para levantar esas masas de la abyección en que se encuentran". Por lo tanto, había que reconocer que la sociedad peruana no estaba preparada para la introducción de novedades tan trascendentales como el sufragio directo, porque "el voto directo supone república y supone instrucción en las masas, y ni república ni instrucción tenemos"97.

Cuando después de la guerra se volvió a discutir sobre el sufragio y las leyes electorales, la situación general y el clima cultural habían cambiado profundamente. La voluntad de las élites de emprender un camino de rápida modernización -que en este período parecía que estaba a la mano- produjo por un lado un fuerte deseo de conseguir la estabilidad política y social, premisa indispensable del progreso, y por otro un sentimiento de repulsión hacia los elementos que se consideraban como un obstáculo. Con respecto a los indígenas, estos sentimientos, fortalecidos por el miedo y la desconfianza producidos por las revueltas que se habían desarrollado a lo largo de toda la faja andina en los años de la guerra y sobre todo de la postguerra, encontraron justificación y legitimación en las doctrinas pseudocientíficas del darwinismo social, que -llegadas de Europa- se habían difundido en toda América Latina $^{98}$. En los ambientes académicos de Lima se pronunciaron en esos años discursos como aquel en que Mariano H. Cornejo, catedrático de la Facultad de Letras de la Universidad de San Marcos, hizo una comparación entre el hombre blanco, a quien concebía como "la manifestación más alta de la potencia vital del planeta, dueño del privilegiado cerebro caucasiano", gracias al cual había alcanzado los más altos ideales religiosos y las especulaciones más sintéticas y comprensi-

96 Congreso Ordinario de 1878, Diario de los Debates de la H. Cámara de Diputados, Lima, Imprenta "El Nacional", 1878, 715.

97 Ibid., 702, 717, 718 y 738 .

98 Indicaciones bibliográficas sobre el tema de la recepción del pensamiento racial europeo en Hispanoamérica se encuentran en Quijada, “QQue nación?”, op . cit., 47, nota 76. Véase también MarieDanielle Demélas, "Darwinismo a la criolla: el darwinismo social en Bolivia, 1880-1910", en Historia Boliviana I/12, Cochabamba, 1981, 55-83, y, de la misma autora, L'invention politique. Bolivie, Equateur, Pérou au XIXe siècle, París, Éditions Recherches sur les Civilisations, 1992, 367-370. 
vas de la filosofía, y el indio, para el cual -según el autor- la edificación de la gran monarquía patriarcal había constituido el esfuerzo supremo que había agotado todas sus energías, dejando encerrado su espíritu "en el molde de una teocracia sin movimiento como ciertos animales inferiores que aunque conservan las formas orgánicas, reemplazan la movilidad de la materia viva con la fijeza de la materia cristalizada"99. Pocos años antes, Luis Carranza, médico fundador y presidente de la Sociedad Geográfica de Lima, había escrito que el indio contemporáneo era "el mismo que el de los tiempos del Imperio, en su carácter intelectual”, que podía considerarse "en el orden de los tipos morales, lo que el mahamud conservado en las nieves del mar siberiano, es en el orden de los tipos orgánicos"100. Si para Bartolomé Herrera los indios necesitaban de instrucción para transformarse en electores libres y responsables, para Clemente Palma, en cambio, ellos constituían una raza "sin carácter [...] apática, sin aspiraciones [...] inadaptable a la educación"101.

Hay que tener en cuenta el hecho de que aun el indigenismo republicano había presentado elementos de ambigüedad. Como ha escrito Basadre, con expresión felizmente sintética, la generación de la Independencia creyó "encontrar en lo indígena los dos elementos que anhela como raíz nutricia todo nacionalismo: el pueblo y el pasado"102. El pueblo -o sea las masas indígenas- permitía no reducir la Independencia a una empresa de pocos grupos, mientras que el glorioso pasado incaico servía para proporcionar a la nueva nación raíces que provenían de tiempos inmemoriales, singularizándola frente a las otras repúblicas cercanas, también recién constituidas. Pero, como escribe Cecilia Méndez, comentando la actitud despectiva de la élite limeña con respecto a Andrés de Santa Cruz durante la época de la Confederación Perú-Boliviana, se aceptaba al indio mientras constituyera una gloria lejana, abstracta y remota, mientras que se lo consideraba bruto, estúpido y vándalo si se encontraba presente y activo, como Santa Cruz ${ }^{103}$.

Sin embargo, a fines del siglo los tonos y los términos empleados son aún más duros. En el debate de los años 90 asoman todavía, en las palabras de los que se oponen a la reforma del texto constitucional, referencias a la falta de educación y a las responsabilidades de los gobernantes ${ }^{104}$; no obstante, todos están de acuerdo en la definición de los indígenas como una "raza desgraciada [que] reúne a su igno-

99 Mariano H. Cornejo, "Principios generales de la sociología. Discurso académico de apertura del año universitario de 1899", en Anales de la Universidad Mayor de San Marcos de Lima XXVII, Lima, Imprenta Liberal, 1900, 32.

100 Luis Carranza, "Apuntes sobre la raza indígena. Condiciones físicas e intelectuales del indio", en Boletín de la Sociedad Geográfica de Lima II:II, Lima, Imprenta de F. Masías, 1892, 28-39. El texto fue publicado nuevamente en La ciencia en el Perú en el siglo XIX. Selección de artículos publicados por el Dr. Luis Carranza, médico fundador y presidente de la Sociedad Geográfica de Lima, tomo I, Lima, [s.n.], 1988, 121-135: 123-124.

101 Clemente Palma, El porvenir de las razas en el Perú, Lima, 1897, citado en Alberto Flores Galindo, Perú: identità e utopia. Cercando un Inca, Firenze, Ponte alle Grazie, 1991, 202.

102 Basadre, Historia de la República del Perú, op. cit., I:263.

103 Cecilia Méndez, "Incas sí, indios no; Notes on Peruvian Creole Nationalism and its Contemporary Crisis", en Journal of Latin American Studies 28, Cambridge, 1996, 197-225: 210.

104 Congreso Ordinario de 1890, Diario de los Debates de la H. Cámara de Senadores, op. cit., 651 y 655 . 
rancia absoluta las especiales condiciones en que vive". Son seres "inocentes, sumisos, ignorantes", "hombres que no pueden llamarse tales"105. Una intervención merece ser citada extensamente: si alguien -dijo Juan F. Pazos, diputado por Hualgayoc- tratara de asustar a la Cámara insinuando la posibilidad de que esa gran masa de población algún día pudiese "caer sobre nosotros [...] y destrozar en un instante nuestra copiada y orgullosa civilización europea", se podía tranquilamente contestar que se trataba de una amenaza inexistente:

“¿Nuestros humildes y desgraciados indígenas, van a sublevarse [...] porque les privamos de un derecho que no han ejercido nunca, que no ejercerán tampoco, mientras continúen en ese estado de ignorancia verdaderamente dolorosa? [...] Si en vez de concederles el derecho de sufragio, les concedierais aun mayores, poco se cuidarán de aceptarlos, desde que no están en armonía con sus costumbres".

Si alguien preguntara a los indígenas si les interesaba el derecho de votar, "os mirarán con soberbia indiferencia"; si se les hablara de libertades públicas, "ellos os contestarán que no desean otra libertad que la del aire, que la del frío refrescador de las punas, que solo desean que nadie ponga mano odiosa en sus personas, que los dejen libres y satisfechos, con sus pequeñas necesidades" ${ }^{106}$. Así, el acento parece estar intencionalmente puesto no solo en la incapacidad e ignorancia del indio, sino también en su supuesta indiferencia, en sentirse ajeno a un proyecto común, en la diferencia de costumbres y expectativas, en su inutilidad -en fin- respecto de las inquietudes del momento. El señor Pazos agregaba que, sin embargo, era indispensable crear necesidades al indígena, porque "hasta que [...] no monte a caballo, no fume cigarrillos, no sienta aquellas exigencias que se originan de la mayor ilustración relativa, $[\ldots]$ no se concibe que llegue á ser un ciudadano"107.

Dos aspectos llaman la atención. Por un lado, el hecho de que en el debate no aparezca alguna referencia a las revueltas violentas -aún no concluidas-, a las ocupaciones de haciendas y a los intentos de autogobierno puestos en marcha por las comunidades indígenas en algunas regiones del interior ${ }^{108}$. Como hace notar Thurner, una vez más se había verificado un cambio repentino en el discurso: el 'indio bravo', que solo unos años antes hacía temblar a los 'blancos' de pequeñas ciudades de varias provincias andinas, en departamentos como los de Cajamarca, Áncash y Junín, se había vuelto el 'indio manso y sumiso', incapaz de iniciativa política autónoma, sin historia e inútil para cualquier proyecto nacional que quisiera involucrarlo ${ }^{109}$.

105 Congreso Ordinario de 1891, Diario de los Debates de la Cámara de Diputados, s.p.i, 518.

106 Ibid., 465, 601, 604 y 605.

107 Ibid., 604.

108 Véase, para citar solo el trabajo más reciente de Florencia Mallon sobre este tema, Peasant and Nation. The Making of Postcolonial Mexico and Peru, Berkeley, University of California Press, 1995.

109 Thurner, op. cit., 133. Esta imagen del indio andino como un "ser humano cultural y socialmente diferente, inmutable y silencioso, inextricablemente enraizado en el ambiente telúrico del paisaje andino", dominado por las pasiones y por taras ancestrales, desprovisto de un "claro concepto de la nación", será propuesta nuevamente en las primeras décadas del siglo siguiente, cuando los levanta- 
Por otro lado, esta imagen distorsionada de la población indígena, representada como un todo indiferenciado, caracterizado por la falta de civilización, pertenece a una especie de koiné, a un lenguaje común utilizado en otros países cercanos, como Argentina y Chile, en los cuales la población indígena no era mayoritaria, pero que en tiempos recientes habían visto la conclusión de operaciones definidas con términos como la 'Conquista del Desierto' en Argentina o la 'Pacificación de la Araucanía’ en Chile ${ }^{110}$. En ambos países, las poblaciones indígenas eran descritas no solo en términos despectivos y racistas, sino de manera tal que no se respetaba mínimamente su realidad, a pesar de ser esta bien conocida por los que escribían sobre ella111; es como si esta "visión urbana de los Andes" -para emplear las palabras de Efraín Kristal ${ }^{112}$ - voluntariamente quisiera falsificar la realidad, para alejar todavía más toda posibilidad de diálogo, de comunicación, de común -aunque conflictiva- pertenencia.

Se puede concluir que, para proceder "en armonía con el espíritu del siglo", al servicio de los intereses del país, de las aspiraciones de las clases más cultas y de la libertad "bien entendida"113, la 'nación cívica' de mediados del siglo XIX fue sustituida, a fines de dicha centuria, por la 'nación civilizada'. Como señala Quijada, "la nación cívica, que había sido imaginada como una construcción incluyente, da paso a la nación civilizada, cuya imagen se irá asociando paulatinamente a la exclusión 'necesaria' de los elementos que no se adapten a ella", condición ineludible para llegar, por fin, a la construcción de una comunidad que se suponía unida en sus aspiraciones y a la afirmación de una identidad colectiva homogénea ${ }^{114}$.

mientos indígenas pusieron la cuestión indígena en el centro de los debates acerca de la identidad peruana y de las preocupaciones de sujetos aun muy diferentes, como los indigenistas cusqueños, los criminólogos positivistas, el gobierno (el de Augusto B. Leguía en particular), la Iglesia, los hombres de negocios dedicados al turismo, etc. Véase Deborah A. Poole, "Ciencia, peligrosidad y represión en la criminologá indigenista peruana", en Carlos Aguirre y Charles Walker (eds.), Bandoleros, abigeos y montoneros. Criminalidad y violencia en el Perú, siglos XVIII-XX, Lima, Instituto de Apoyo Agrario, 1990, 335-393: 340, 357, 367.

110 En Bolivia, el debate sobre el problema indio, central al comienzo del siglo XX, tomó matices distintos. Aún en este país, en las obras de autores importantes como Alcides Arguedas, Franz Tamayo, Rigoberto Paredes (que sin embargo presentan aspectos muy diferentes) el indio aparece como un sujeto empobrecido, desafortunado, iletrado e incivilizado, quien permanece al margen de la economía de mercado, desinteresado e incapaz de cualquier iniciativa mercantil o productiva. Pero las críticas más duras se dirigen al mestizo, al "cholaje", inmoral y peligroso, símbolo de todo lo negativo del país. Escribe Larson que "estos escritores transfiguraron la dicotomia indio/mestizo en una antítesis biocultural y racial: el silencioso pasivo y prepolítico indio yuxtapuesto con el parasítico, letrado, cabalgante y politicamente activo cholo". Véase Brooke Larson, "Indios redimidos, cholos barbarizados: Imaginando la modernidad neocolonial boliviana (1900-1910)", en Dora Cajías, Magdalena Cajías, Carmen Johson e Iris Villegas (comps.), Visiones de fin de siglo. Bolivia y América Latina en el siglo XX, La Paz, IFEA, 2001, 27-48: 40.

111 Consultar sobre el tema los artículos de Mónica Quijada, ¿QQué nación?”, op. cit., en particular las páginas 47-49, y “La 'ciudadanización’ del indio ‘bárbaro'. Políticas oficiales y oficiosas hacia la población indígena de la Pampa y la Patagonia, 1870-1920”, en Revista de Indias LIX:217, Madrid, 1999, 675-704: 685-692.

112 Efraín Kristal, Una visión urbana de los Andes. Génesis y desarrollo del indigenismo en el Perú, 1848-1930, Lima, Instituto de Apoyo Agrario, 1991.

113 Congreso Ordinario de 1891, Diario de los Debates de la Cámara de Diputados, op. cit., 605606.

114 Quijada, ¿¿Qué nación?”, op. cit., 50. 


\section{CONCLUSIONES}

La reforma de 1895 había tenido consecuencias importantes. En primer lugar, había permitido una reducción importante del número de los ciudadanos con derecho a voto y la consecuente introducción del sufragio directo. Los analfabetos, en su mayoría indígenas, habían sido excluidos de la vida política, en la cual no volverían a ingresar hasta la aprobación de la Constitución de 1979. Sin embargo, este no había sido sino el medio utilizado para lograr el objetivo más deseado, es decir, la construcción de un cuerpo electoral capaz de seleccionar representantes que estuviesen en armonía con el proyecto modernizador diseñado por la élite política. Considerando en conjunto todos los cambios que habían ocurrido -desde la restricción del sufragio a la nueva geografía política, la nueva figura del ciudadano y la renovada selección del personal político y de gobierno-, se puede afirmar que en esta fase, y no antes, hay que colocar el nacimiento del régimen oligárquico peruano, de esa 'república aristocrática' en la cual -para citar una vez más a Basadre- "el poder verdadero estuvo en los hacendados del norte, sobre todo productores de azúcar y de algodón, siempre que operaran vinculados a Lima, en conjunción con propietarios urbanos y con conspicuos profesionales en relación con ellos"115.

Mientras tanto se abrían nuevos problemas, que quedarían como una pesada herencia para el nuevo siglo: el de la colocación que había que dar a la población indígena en la sociedad y el de su estatus político. En el debate de 1891 se habían escuchado también algunas voces, quizás interesadas, que habían sostenido la inoportunidad de una reforma que privaba de los derechos políticos a aquella "raza que es la base de la nación, [...] de su vida financiera y de su vida política [...] porque ellos soportan el servicio militar, la más difícil de las cargas"116. Cesáreo Chacaltana, diputado por Tarma, expuso en la asamblea las fuertes dudas que tenía acerca de la contradicción que se creaba entre los postulados básicos de la Constitución y la nueva norma que se quería aprobar. Según la Constitución -afirmó-,

"la soberanía reside en la Nación [que es] la asociación política de todos los peruanos [...]. ¿Y por qué, si la soberanía está radicada en todos los peruanos hemos de eliminar á unos de los comicios electorales, arrebatándoles el derecho de sufragio, que es precisamente aquel por medio del cual ejerce el pueblo sus funciones soberanas?”.

En realidad se estaba creando una situación en la cual la soberanía no residía en la nación, sino en una minoría de ella, con lo cual se falseaba uno de los principios fundamentales de la Constitución. Chacaltana preguntó, además, por qué se llamaba ciudadanos en ejercicio a los que se quería privar del sufragio, y agregó la siguiente interrogante: "¿qué derechos van a ejercer estos ciudadanos en ejercicio?"117.

115 Jorge Basadre, Introducción a las bases documentales para la historia de la República del Perú: con algunas reflexiones, Lima, Ediciones P. L. Villanueva, 1971, II:630.

116 Congreso Ordinario de 1891, Diario de los Debates de la Cámara de Diputados, op . cit., 465.

117 Ibid., 542-543. Las cursivas son del original. 
Pero las anteriores no eran las únicas amenazas que se cernían sobre los indígenas. En 1889 fue presentado un proyecto de ley sobre la repartición de las tierras de comunidad, acompañado por un informe sobre los Inconvenientes que ofrece la organización actual de las tierras de comunidad, en el cual, entre otras cosas, se afirmaba que tal organización "impide el desarrollo de la industria" y hace que "una gran parte de la riqueza pública quede inmobilizada y no contribuya al aumento de la fortuna general"118. En el mismo año, el prefecto del departamento de Huánuco envió a Lima un Informe sobre la consulta hecha por el Director de Gobierno, sobre si conviene o no la abolición de las comunidades indígenas. El prefecto consideraba "inaplicable al presente" la reforma, por razones cuya explicación sobrepasaría los límites del presente trabajo; sin embargo, el documento es síntoma evidente del hecho de que la presencia de las comunidades indígenas era percibida en esta época como un obstáculo para el desarrollo de la economía, además de que permite vislumbrar el clima político que existía alrededor de las comunidades mismas y de sus tierras ${ }^{119}$.

En 1893, finalmente, una resolución legislativa desempolvó los decretos de 1824, según los cuales los indígenas tenían que ser considerados propietarios individuales de las tierras comunitarias, y estableció que, "con arreglo a la ley sobre contribución predial, no están obligados a pagarla si las rentas que sus tierras les producen no alcanzan a la suma de cien soles anuales"120. En 1895, casi como un corolario de la reforma del artículo 38 de la Constitución, se abolió definitivamente la contribución personal. Ya en 1890, el entonces ministro de Hacienda y Comercio, Eulogio Delgado, había afirmado que las tierras de los indígenas, "poseídas en común, no tienen ya razón de existencia por haber desaparecido el tributo impuesto a los indígenas, que para facilitarles el pago les fueren dadas. A la presente, no son sino causa frecuente de discordias, y rémora para el adelanto de la agricultura"121.

Bien mirado, y considerando todas las medidas que se aprobaron en este período, se abren dos nuevas cuestiones. En primer lugar es lícito preguntarse si, siendo privada de la posibilidad de ejercer el derecho de sufragio y también de la condición de contribuyente, empujada hacia los márgenes de la sociedad y del Estado, la mayoría de la población indígena podía ser considerada todavía como titular de la ciudadanía en el sentido liberal de la palabra. La segunda cuestión se refiere a las reacciones de los indígenas frente a la privación del sufragio. En 1931, Manuel

118 BNP, SI, D12842, Proyecto de ley sobre la repartición de tierras de comunidad. Tarma, Julio 11 de 1889 .

119 BNP, SI, D11197, Informe del Prefecto del Departamento de Huánuco sobre la consulta hecha por el Director de Gobierno, sobre sí conviene o nó la abolición de las comunidades indígenas. Huánuco, Enero 25 de 1889.

120 "Resolución legislativa declarando que los indígenas de la República son legítimos propietarios de los terrenos que poseen en virtud de las leyes de 1824 y demás de la materia; y que solo pagan contribución predial si estas producen cien soles anuales", en José M. Rodríguez, Anales de la Hacienda Pública del Perú, Historia y Legislación fiscal de la República, tomo XXIV, Lima, Litografía y Tipografía T. Scheuch, 1926, 112A-113A.

121 Eulogio Delgado, Memoria de Hacienda y Comercio presentada al Congreso Constitucional de 1890 por el Ministro del ramo, en Rodríguez, op. cit., XXI:74. 
Vicente Villarán, jurista y hombre político, publicó en El Perú un breve artículo intitulado "El voto del indio y la geografía electoral", en el cual escribía: "Nuestra realidad comprobada, conocida es que el indio analfabeto no vota, ni ha votado nunca. Tuvo derecho de sufragio y nunca se percató de ese derecho ni lo usó ni lo defendió" 122 .

Estas palabras, proyectadas hacia adelante y hacia atrás en el tiempo, retomadas por historiadores como el mismo Jorge Basadre, han sido por mucho tiempo el paradigma interpretativo único. Con respecto a la participación de los indígenas de los pueblos y comunidades en las jornadas electorales a lo largo del siglo XIX, algo se ha investigado y escrito en tiempos recientes, que ha llevado a cuestionar las afirmaciones de Villarán ${ }^{123}$, pero nada se sabe en realidad acerca de eventuales reacciones a la aprobación de la reforma de 1895, porque este aspecto no ha sido estudiado.

Indudablemente, las comunidades indígenas se encontraban en aquellos años bajo múltiples ataques, pues -como se ha dicho- las transformaciones económicas realizadas y por realizar en aquellos años (junto con la presencia de nuevas infraestructuras, como los ferrocarriles, y el crecimiento demográfico) estaban ejerciendo una fuerte presión sobre todos sus recursos (tierra, agua, mano de obra, ganado). Esto acaecía en todas las regiones del país, desde el norte, donde la pujante economía del azúcar y el algodón requería mano de obra y agua, hasta el sur, donde se desarrollaba cada vez más el comercio de las lanas, pasando por el centro, región en la cual las empresas norteamericanas empezaban a ingresar en los negocios de la minería y la ganadería.

El problema del sufragio, por lo tanto, tenía que ocupar una posición secundaria entre los intereses de los indígenas. Aun así, no hay que olvidar que en los años siguientes, durante la 'cruzada' civilista dirigida a la 'civilización' del indio -es decir, su castellanización a toda costa-, grande fue el esfuerzo desarrollado por los sectores campesinos para mejorar su "equipaje educativo"124 (y, por lo tanto, adquirir la alfabetización y la posibilidad de sufragar), demandando al Estado mayores prestaciones de servicios u organizándolos ellos mismos. Es posible que las repercusiones fueran percibidas sobre todo en el ámbito local, por los indígenas de pueblos y comunidades, porque tuvo que resquebrajarse todo un tejido de relaciones que, aunque probablemente desventajosas y asimétricas, de todas maneras habían vinculado a los indios con los otros segmentos étnicos de las sociedades locales. No obstante, es posible también suponer que en este contexto no se hayan dado muchos cambios; esto porque los notables indígenas, en su mayoría, sabían leer y escribir y, por lo tanto, aun después de las reformas de 1895-1896, pudieron seguir sufragando y participando en las dinámicas políticas. Una pista muy sutil en esta dirección es la que proporcionan los ya citados registros de electores munici-

122 El ensayo de Villarán fue publicado nuevamente en Manuel Vicente Villarán, Páginas escogidas, Lima, Talleres Gráficos P. L. Villanueva, 1962, 233-236: 234.

123 Véase nota 3.

124 Véase Contreras, "Maestros, mistis y campesinos en el Perú rural", op. cit., 215. 
pales de los distritos de Chuschi y Vischongo ${ }^{125}$, comparados con las actas del colegio electoral de la provincia de Cangallo (a la cual los dos distritos pertenecían) relativas al año 1892 y, por ende, anteriores a las reformas que venimos comentando ${ }^{126}$. Un ciudadano inscrito en el registro de Chuschi (por lo tanto alfabetizado, porque en aquel registro se encuentran solo los nombres de los que podían sufragar en las elecciones municipales, para lo cual, de acuerdo con la ley de 1892 , se requería la alfabetización) ${ }^{127}$ y clasificado como "natural de Chuschi", Mariano Pacotaipe, se encuentra en función de elector de segundo grado de su parroquia en aquel colegio provincial; lo mismo pasa con un ciudadano de Vischongo, Santiago Quispe, clasificado como "natural" y alfabetizado. Es muy probable que estos dos sujetos siguieran sufragando y representando a sus comunidades aun después de la restricción del sufragio; lamentablemente, hasta el momento no ha sido posible encontrar documentos que confirmen esta hipótesis. Otros nombres indígenas de ciudadanos de los distritos de Canaria y Huancarailla aparecen en los respectivos registros de electores municipales y en las actas de Cangallo. No obstante, como en el caso de estos dos distritos los registros no proporcionan informaciones precisas sobre la pertenencia étnica, es mejor no llegar a conclusiones apresuradas. De todos modos, son datos que nos motivan a seguir investigando.

125 BNP, SI, D5565, Duplicado del Registro de Electores municipales de los distritos de Vischongo, Totos, Chusqui [sic], Canaria, Colca, Paras, Huancarailla, y cercado de Cangallo. Ayacucho, Marzo 9 de 1893.

126 ACP, Diputados 1892, legajo 1, Ayacucho-Cangallo, Acta de la elección de un diputado propietario por la provincia de Cangallo, Lima, Junio 30 de 1892.

127 Con respecto a esta ley de municipalidades, véase la nota 36. 